\title{
The Argument Form "Appeal to Galileo": A Critical Appreciation of Doury's Account
}

\author{
Maurice A. Finocchiaro
}

Department of Philosophy

University of Nevada, Las Vegas

Las Vegas, NV 89154-5028

USA

maurice.finocchiaro@unlv.edu

\begin{abstract}
Following a linguisticdescriptivist approach, Marianne Doury has studied debates about "parasciences" (e.g. astrology), discovering that "parascientists" frequently argue by "appeal to Galileo" (i.e., defend their views by comparing themselves to Galileo and their opponents to the Inquisition); opponents object by criticizing the analogy, charging fallacy, and appealing to counter-examples. I argue that Galilean appeals are much more widely used, by creationists, globalwarming skeptics, advocates of "settled science", great scientists, and great philosophers. Moreover, several subtypes should be distinguished; critiques questioning the analogy are proper; fallacy charges are problematic; and appeals to counterexamples are really indirect critiques of the analogy.
\end{abstract}

Résumé: En poursuivant une approche linguistique-descriptiviste, Marianne Doury a étudié les débats sur les «parasciences» (par exemple, l'astrologie), et a découvert que les «parasavants» raisonnent souvent en faisant un «appel à Galilée" (c.-àd. ils défendent leurs points de vue en se comparant à Galileo et en comparant leurs adversaires aux juges de l'Inquisition). Les adversaires des parasavant critiquent l'analogie en la qualifiant de sophisme, et en construisant des contreexemples. Je soutiens que les appels à Galilée sont beaucoup plus largement utilisés, par des créationnistes, des sceptiques du réchauffement planétaire, des défenseurs de la «science établie», des grands scientifiques, et des grands philosophes. En outre, on doit distinguer plusieurs sous-types; les critiques de l'analogie sont appropriées; les accusations de sophisme sont problématiques; et les contre-exemples sont vraiment des critiques indirectes de l'analogie.

Keywords: analogy, appeal to Galileo, appeal to unpopularity, Benveniste, Marianne Doury, Einstein, Galileo, Hume, parasciences, precedent

\section{Introduction}

In a number of well-known articles, Marianne Doury has advocated and practiced an approach to the study of argumentation that is empirical, linguistic, and descriptive (Doury 2005, 2006, 
2009, 2013, 2014). Such an approach belongs explicitly (and historically and sociologically) to a school or tradition that is widespread among French-speaking scholars, such as Christian Plantin, whose work has had a direct influence on Doury (Plantin 1990, 2005, 2011; Amossy 2009; cf. Eemeren et al. 2014, pp. 479-515). However, Doury's approach could also be regarded as implicitly belonging to the family of orientations which are not uncommon in the English-speaking world and others would generally call historical and empirical (Goodwin 2007; Finocchiaro 2005, pp. 14-15, 34-91; cf. Eemeren et al. 2014, pp. 38790).

Following such an approach, Doury has made a significant monograph-length study of the debates and controversies surrounding what she calls "parasciences" (Doury 1997). These are subjects like astrology, which claim to be scientific and to have discovered various truths about the world, but which are generally rejected by the scientific establishment and intellectual elites. Such subjects are frequently called pseudosciences, and sometimes "pathological sciences" (Langmuir 1953), but I shall follow her terminology. Doury's study of the debates over parasciences is not as well-known as her more general and programmatic essays, perhaps because it is available only in French. However, it contains at least one interesting and important discovery, which deserves greater dissemination and critical appreciation.

Doury's study of parasciences reveals that partisans of parasciences make frequent use of a special type of argument, which she labels "appeal to Galileo" (Doury 1993; 1997, pp. 143-65). Thus, a principal strand of her study is an account of this argument form. What I plan to do here is first to summarize Doury's account, making sure to give enough quotations to convey its flavor; then I shall add a number of empirical and historical amplifications, elaborations, and confirmations, meant to suggest that appeals to Galileo are even more common and important and deserve more philosophical attention; and finally I shall undertake some constructive criticism, elaborating additional conceptual distinctions, needed evaluations, and theoretical refinements.

\section{Doury on the "appeal to Galileo"}

In the type of argument which Doury calls "appeal to Galileo," what happens is that advocates of the parasciences compare 
themselves to Galileo, and their opponents to the Inquisition; their aim is to suggest that their parascientific claims should be accepted, or at least that their opponents should suspend judgment, until future research settles the issue. In other words, proponents of the parasciences appeal to Galileo's trial, making a plea that they be allowed the freedom to advocate their views, and that their opponents not repeat the error of Galileo's inquisitors. Doury's account of the appeal to Galileo consists of an explanation of her general approach; an analysis of this argument form as an argument from analogy, including a description of the ways in which opponents attempt to refute it; a wealth of concrete examples, taken mostly from a corpus of debates broadcast on French TV; and occasional illustrations from a special controversy known as the Benveniste affair, which it will be useful to summarize more explicitly.

\subsection{Doury's approach}

Although I have already mentioned some essential features of Doury's approach that can be readily gleaned from her Englishlanguage articles, it is useful to add some nuances and elaborations which she discusses explicitly in her French-language monograph on parasciences debates (Doury 1997, pp. 13-19). In conceiving argumentation as a linguistic phenomenon, she means to contrast this to viewing it as a mental process. In viewing argumentation from a descriptive perspective, the intended contrast is a normative perspective; but such a viewpoint should be understood as including the description of arguers' normative practices, and excluding only analysts' formulation and justification of general normative principles. Thirdly, there is "the choice between a view of argumentation as a means of reaching consensus, or as a manifestation of an irreducible dissensus" (Doury 1997, p. 14); and here, she discards the viewpoint of consensus, and focuses on dissensus. Next, Doury (1997, p. 14) advocates "a rhetorical (and not logicist) conception of argumentation"; and this amounts to a sensitivity to, or focus on, persuasion, context, and practical action. Fifthly, argumentation involves not merely a dialogue between two interlocutors, but a triangular or tripolar situation, that is, the two opponents plus an audience. Finally, the approach is reciprocal or interactionist, in the sense that "one can try to characterize a type of argument by means of the refutations which it allows and of those which it excludes" (Doury 1997, p. 18).

It is also useful to have an overview of the "corpus," or 


\section{Finocchiaro}

data base, which she examines by following the approach just sketched (Doury 1997, pp. 21-26, 253-54). The corpus consists primarily of television broadcasts of extended debates on parasciences that took place in France in the period 1988-1993; they number about thirty, and were recorded and transcribed. Doury is aware that the actual discussions are more complicated than one might think from the transcriptions, and have other aspects which she neglects; but she argues plausibly that such limitations and focus are legitimate. For example, the moderator and producer of such TV programs have a role in what is broadcast; and there are issues about whether the debate participants accept and comply with the rules defined by the organizer. Moreover, the debate participants display behavior such as gestures and facial expressions that is usually ignored in the transcriptions of the text; and they often have other motivations in addition to the discussion of the issues.

The corpus also includes, to a secondary extent, printed articles in popular media having wide circulation and in militant or technical media having small circulation, as well as selected passages in books on the parasciences.

One final preliminary requires us to say a little more about the "parasciences" (Doury 1997, pp. 19-21, 27-51). Besides astrology, already mentioned, there are such other subjects as numerology, palmistry, parapsychology, homeopathy, and alternative medicines. There is no need to describe these in any more details here; suffice it to have this list of names to convey a general idea of the family resemblance. However, Doury also makes references to, and gives examples from, another topic that shares many characteristics, but is in some important respects different. The topic is the so-called "Benveniste affair."

\subsection{The Benveniste affair}

Since the Benveniste affair is less well known, and is not explicitly summarized by Doury, it deserves some words of explanation. Moreover, this affair involves some very technical content and factual points in biology, immunology, and medical science, which need to be highlighted, although for our purpose here they need not be mastered or completely understood. Doury presupposes these facts, but I found that I had to retrieve them, partly from her own secondary sources (Alfonsi 1989, Kaufmann 1993, Pracontal 1990), and partly from the original primary sources (Benveniste 1988a, Benveniste 1988b, Davenas et al. 1988, Maddox 1988a, Maddox 1988b, Maddox et al. 1988). 
In 1988, the prestigious journal Nature published a brief paper co-authored by thirteen immunologists from four countries (Davenas et al. 1988). The lead author was a Frenchman named Jacques Benveniste, who was the director of a research laboratory at the French National Institute of Health and Medical Research, near Paris; and in fact most of the other co-authors made up his collaborators at the laboratory. The three-page paper was primarily a report on a series of experiments originating from Benveniste's lab, but later reproduced in two other labs in Israel, a fourth one in Italy, and a fifth one in Canada.

To even glimpse at these experimental results, some background is needed. They deal with allergic reactions, their causes, and their effects. In allergic patients, their blood produces an abnormally high amount of an antibody called immunoglobulin $\mathrm{E}(\mathrm{IgE})$. Antibodies are proteins produced in the human body to fight foreign substances such as bacteria, viruses, and other proteins. IgE is a particular type of antibody that plays a crucial role in allergic reactions. When an allergy-causing substance (called an allergen) comes in contact with $\operatorname{IgE}$, the blood releases large amounts of substances that produce various symptoms. The process of release is called degranulation, and one of the most important of these substances is called histamine. The extent of degranulation and the amount of histamine produced can be observed in various ways with a microscope. The process of degranulation and histamine production is triggered not only by allergens, but also by many other foreign substances belonging to a more general class, labeled "antigens."

In the Benveniste experiments, samples of human blood were exposed to an anti-IgE antigen derived from goats. The amount of degranulation was measured (by microscopic observation) for various amounts of this antigen. Diminishing quantities of the latter were produced by first starting with a certain small amount, then dissolving it into a given working volume of pure water, and then repeatedly diluting again in pure water a portion of the resulting amount. Typically, a ten-fold dilution was produced by taking one-tenth of a given solution and dissolving it anew into a new sample of the given working volume of pure water. Such serial dilutions were repeated usually 60 times, and sometimes 120 times.

The surprising and baffling phenomenon was that degranulation continued to occur even when the original amount of anti-IgE antigen had been diluted so many times that there were no longer any molecules of it left in the water. Benveniste and his team tried to explain this effect as due to the water acquiring 
some kind of memory of having previously contained some molecules of the antigen. Thus the resulting affair is sometimes also called the controversy over "the memory of water."

However, before trying to explain the effect, its reality or existence was hard to accept. To appreciate this, one must understand how the alleged effect seemed to contradict the most fundamental laws of physics and chemistry. In light of the atomic and molecular theory of matter, any amount of any substance contains a finite number of molecules. More precisely, this number is equal to the so-called Avogadro's number for an amount of a substance in grams equal to its molecular weight. For example, water $\left(\mathrm{H}_{2} \mathrm{O}\right)$ has a molecular weight of 18 , and so 18 grams of water contain Avogadro's number of molecules; this number is known to be $6.02 \times 10^{23}$. For the present context, we may round this off to $10^{24}$.

The molecular weight of the anti-IgE antigen is different, but of the same order of magnitude as that of water. So we can suppose that we start the Benveniste experiments with an amount of the antigen containing Avogadro's number $\left(10^{24}\right)$ of molecules. For the sake of concrete illustration, let us say this original sample of antigen is about one liter. The first dilution would dissolve this sample into 10 liters of pure water. From the resulting solution we take about one-tenth, namely one liter. This once-diluted one liter of antigen now contains $10^{23}$ $\left(=1 / 10 \times 10^{24}\right)$. After the 24th dilution, one liter of the solution will probably contain just 1 molecule of antigen $\left(=\left[1 / 10^{24}\right] \times 10^{24}\right)$. Further dilutions will generate solutions that almost certainly do not contain any molecules of the antigen. And yet, Benveniste and his team claimed that this non-existent antigen continued to produce degranulation well into the 60 -fold dilution, and even 120-fold dilution.

This 1988 paper had been under review with the journal Nature for about two years, and had received unfavorable evaluations, and had undergone some revisions. Eventually, the editor (physicist John Maddox) decided to publish it, with the understanding that soon after publication an investigating team selected by the journal would visit Benveniste's lab, to check the integrity and rigor of the experimental procedures. The paper appeared in the issue of June 30, accompanied by one-paragraph "Editorial Reservation," printed immediately after the paper, on the last page. Moreover, in another section of the same issue there was an editorial, advising suspension of judgment about Benveniste's results (Maddox 1988b).

The investigating team visited Benveniste's lab in July. 
They first simply watched him and his collaborators reproduce their results as previously described and published. However, the investigators then instituted various controls designed to "blind" the various samples of antigen and solutions being processed and analyzed. Such "blinding" meant that, for example, the researchers doing the dilutions did not know whether they were diluting the antigen for the first time, or the 24th time, or the 60th, or the 120th; similarly, the researchers observing with a microscope the amount of degranulation did not know whether they were observing a solution diluted just one, or one diluted 24 times already, etc. The original results could not be reproduced with these more rigorous blinded procedures.

Thus, the investigating team concluded that the original results had been obtained because of such things as observational errors, theoretical bias, and statistical sloppiness. They published their report in the issue of Nature of 28 July 1988 (Maddox et al. 1988). Benveniste was unconvinced and unmoved, and he was allowed to reply (Benveniste 1988a). The journal continued to be flooded with letters to the editors, as it had been after the original publication; these were mostly negative and critical of Benveniste's claims, and tried to explain his experimental results as artifacts generated by his sloppy procedures (Kaufmann 1993, p. 76). Finally, the journal put an end to these discussion by announcing on October 27 that it would no longer publish anything on the topic (Maddox 1988a, Benveniste 1988b). Although that was the end of Nature's involvement in the affair, the controversy continued for several more years, mostly in France but to some extent internationally; this happened in general popular media, in media of scientific popularization, and to some extent in other technical scientific publications. Benveniste (who died in 2004) never accepted defeat; instead, he viewed himself more and more as a new Galileo, of which more below.

Finally, it is worth mentioning one of the many things that add interest and spice to this controversy. Many people thought that Benveniste's results provided a scientific basis for homeopathy, and elaborated such a connection, although this was not done by Benveniste himself. In fact, homeopathy (itself one of the "parasciences") is an alternative system of medicine whose key claim is this: a drug that produces in a healthy person the same symptoms as does a particular disease can be used in very small doses to treat that disease. For example, when it was found that healthy persons taking quinine got the same symptoms as patients suffering from malaria, a homeopath would 
prescribe small doses of quinine to cure malaria.

\subsection{Doury's analysis}

In Doury's analysis (pp. 148-50), ${ }^{1}$ the appeal to Galileo is interpreted as a special case of the appeal to precedent, which in turn is regarded as a special case of the argument from analogy. Here, the analogue is not Galileo as such, but rather the trial of Galileo. Following in part Perelman's terminology and conceptualization (Perelman and Olbrechts-Tyteca 1969, pp. 362-68), Doury analyzes the analogue as having not only a model or positive pole (Galileo's behavior), but also an anti-model or negative pole (the Inquisition). Moreover, the conclusion of such an argument can be either strong or moderate: the strong version is that the substantive parascientific claim in question should be accepted; the moderate version is that the substantive parascientific claim should not be rejected or dismissed, but that one should suspend judgment for the time being, and let the future decide.

Additionally, appeals to Galileo are characterized by several features, which amount to ways in which partisans of the parasciences strengthen the analogy, namely justify the premise asserting the analogy. One justification claims or elaborates that the opponents of the parasciences are enemies of intellectual or scientific progress (pp. 152-55). Another justification states or argues that the opponents of the parasciences are being unscientific, motivated by considerations that are religious, or emotional, or economic, or involving other practical interests (pp. 15657). A third justification is a kind of appeal to pity, insofar as it tries to point out that opponents of the parasciences act arrogantly and cruelly against the weak and humble parascientists (pp. 157-58). And a fourth justification tries to portray the proponents of the parasciences as complex and multi-faceted searchers for the truth, who on the one hand are knowledgeable and competent in the conventional and traditional approaches and theories, but who on the other hand have developed a higher loyalty to the truth and become dissidents (pp. 158-60).

Finally, Doury describes three ways in which opponents of the parasciences try to refute appeals to Galileo. As one would expect from the analogical nature of these appeals, one type of attempted refutation is to reject the judgment of analogy be-

\footnotetext{
${ }^{1}$ In this subsection and the next, parenthetical references to Doury's Le Débat Immobile (1997) will be given by means of just the page numbers.
} 
tween the present or target case (parascience) and the precedent or reference case (Galileo's trial); sometimes such refutation is defended with an argument, consisting of pointing out differences between the two cases (pp. 160-61). Another common attempt at refuting the appeal to Galileo consists of trying to show that it amounts to a form of argument that is inferentially invalid: such refutations claim that an appeal to Galileo amounts to "reasoning according to which the unlikelihood of a theory would be a decisive reason for its truthfulness" (Doury 1993, p. $130 ; 1997$, p. 162); and this manner of reasoning is a "pernicious ... aberrant ... paralogism" (p. 162).

A third type of refutation of an appeal to Galileo consists of "answering one precedent with another" (pp. 162-64). That is, sometimes opponents of the parasciences answer by appealing to other cases in the history of science when a theory was at first given some credence, but eventually was falsified and generally rejected. There is no lack of such counter-examples: Doury ( $p$. 163) mentions the alleged discovery of the N-rays by one Prosper Blondot; the case of one Jacques Benoît who claimed to be able to change the hereditary traits of an organism by injecting it with the DNA of an organism of another race; and the case of one William Summerlin, who in the 1970s claimed to be able to transplant black skin onto white mice without rejection. Like the appeal to Galileo, such a countermove can have either a strong conclusion (that the parascientific claim is false), or a moderate one (that one should suspend judgment on the parascientific claim). Doury points out (p. 164) that such an attempted refutation has a strength and a weakness: the strength is that it uses the same argument form as the appeal to Galileo; the weakness is that there is no counter-example which is as famous, notorious, emblematic, and mythological as the example of Galileo.

And this brings us to some aspects of the appeal to Galileo that might be called less logical and more rhetorical than the features just discussed: the fundamental role it has for the parasciences; the fact that the appeal is often more to the myths than to the facts of Galileo's trial; and the irony of appealing to the "father of modern science" to argue against science. In Doury's own words:

The Galileo affair, or more precisely the trial of Galileo, seems to constitute the founding event in relation to which the partisans of the parasciences propose to interpret the debate that brings them in conflict with the opponents of the parasciences.

How is the Galileo affair capable of serving as a refer- 
ence in the debate over the parasciences? As a matter of fact, it seems that the person Galileo, as well as his trial, quickly went beyond the simple historical facts and acquired a mythic dimension. [p. 145] ...

In the debate over the parasciences, the argumentative framework into which the Galileo syndrome finds its way is all the more surprising insofar as it refers to the myth at the origin of the process. Whereas the original stereotype represents the trial of Galileo as the fight of reason against religious obscurantism, in the polemic over the parasciences the appeal to Galileo puts in opposition the scientific community (comparing it to the Inquisition) to the parascientists (who present themselves as being in possession of the truth, in the image of Galileo in his own time, but who are compared by their opponents to the defenders of obscurantism). This turning of Galileo, emblematic figure of modern science, against science itself merits a detailed analysis. [p. 147]

And then Doury goes on to elaborate the analysis which I have already summarized above. In the course of that analysis, she gives a number of examples from her corpus, which so far I have avoided in my own exposition. However, it is time to present her more incisive and relevant illustrations.

\subsection{Doury's examples}

As already mentioned, astrology is a typical parascience, and so it is not surprising to find appeals to Galileo on the part of astrologers in their debates with opponents. Here is an example from an exchange between an astrologer named Élisabeth Teissier and an astronomer named Dominique Ballereau, transcribed by Doury from a French TV program aired on 10 June 1988:

ET: you know who you remind me of? Lord Kelvin, who at the beginning of the twentieth century said 'aviation does not exist, one will never be able to fly because metals are heavier than air ...' That's who you remind me of.

DB: no, no. The two things have nothing to do with each other ... that's a fallacy of confusion. ${ }^{2}$

ET: but they do ... and Galileo then? and Galileo? then ... [p. 150; cf. Doury 1993, p. 126]

\footnotetext{
${ }^{2}$ In French, amalgame; cf. Doury 2005.
} 
Appeals to Galileo are not always as cryptic as this one. For example, in the Benveniste affair, one of his defenders elaborated the following nuanced appeal, where it is obvious that the conclusion is a moderate one (using the distinction made in the analysis summarized above). Doury quotes this passage from Alfonsi (1989, p. 62), who was quoting one Giuliano Preparata:

I think that this is what one should say to people who have violent and emotional reactions (which is something contrary to reason): take a better look! Go and examine Benveniste's test tubes with interest, curiosity, and (why not?) good will! Let us never forget that we are proud to be the heirs of modern science, and that this science began with the heresy of Galileo, with a theory that was absolutely unacceptable for the dominant world view of the time.

One must always maintain this concern: do not be like the official scientists of the time, who committed the great error of refusing to look through Galileo's telescope! [p. 149; cf. Doury 1993, p. 125]

Of course, as I reported in the summary of the Benveniste affair above, the editor of Nature and his team did go and examine his laboratory and apparatus, but failed to reproduce the effect.

Another appeal to Galileo is worth reproducing from Doury because it occurs in the context of a controversy which I have not mentioned so far, but which is accurately added by Doury to the list (parasciences plus Benveniste affair). The controversy is the Lysenko affair, which many authors have indeed compared with the Galileo affair (e.g., Finocchiaro 1989, p. 3). Recall that Lysenko was a Soviet biologist whose theories privileged the role of the environment in human behavior vis-à-vis heredity, and thus they gained wide and official acceptance in the Soviet Union, because they accorded well with the Marxist ideology of the Soviet political system; but that also meant that his scientific opponents who stressed the importance of heredity had a difficult time and were unjustly persecuted. Here is Doury's quotation from a 1988 article entitled "Vavilov: A Soviet Galileo," published in the French journal of scientific popularization Science \& Vie:

Several members of this academy [the Leningrad Academy of Agricultural Sciences] were imprisoned, and the hunting for the 'enemy of the people' Vavilov started. Perfectly aware of the danger that lay in wait for him, Vavilov declared in 1939: 'they can bring us to the stake, 


\section{Finocchiaro}

they can burn us alive, but they cannot make us renounce our convictions'. These words were quoted last November by Pravda, in an article signed by two members of the Academy of Sciences, who said that 'even Galileo did not go that far'. One can add, in defense of the Vatican, that Galileo lived until his natural death at the age of 78 years; but in contrast to Vavilov, he had recanted. [p. 147]

Doury also gives examples of attempts to refute the appeal to Galileo. One of them targets directly the appeal quoted above from astrologer Teissier. Doury quotes the criticism from a book published by one Alain Cuniot. Here we have the second type of criticism, mentioned earlier, which charges something like the fallacy of appeal to unpopularity:

And Galileo? What is it that they all have to do with Galileo? Teissier is a Galileo ... Recently, with his alleged discovery of the 'memory of water', the researcher Benveniste is a Galileo ... It's enough that a delirious person is not followed by the scientific community, and then he can claim to make an appeal to Galileo- the unappreciated one, the martyr who was right. But if Galileo was right, that was not because he was unappreciated, but because he had reason on his side. And it is perfectly possible for someone to be unappreciated, not on account of the fact that one is misunderstood for a while, but simply because one is wrong. [p. 162; cf. Doury 1993, p. 130]

In the next refutation example, we have an illustration of the genre that tries to undermine the premise stating the analogy. Doury quotes it from a book by one Norbert Bensaïd:

One forgets that in the case of Galileo what was being asserted was a scientific truth, born from observation and reason; and that it was being rejected in the name not of reason, but of a revealed religious truth. Nowadays, on the contrary, it is almost always the proponents of revealed truths who object when these revelations are rejected in the name of science, immediately labeled 'official', and of reason, necessarily 'limited'. One also forgets that, after Galileo, there is practically no scientific truth that has been unrecognized, rejected, and persecuted for long. Real discoveries encounter resistance and opposition, which is normal; but neither Pasteur, nor Claude Bernard, nor Einstein, nor Freud died in distress and 
scorned by all. [Doury 1993, pp. 129-30; cf. Doury 1997, p. 161]

Finally, we come to an example that is extremely important and revealing. It relates to the Benveniste affair; that is, Benveniste's own appeal to Galileo made to the editor of $\mathrm{Na}$ ture, Maddox. In fact, two questions immediately arise about that affair, even if one is only superficially acquainted with it: why did the editor publish Benveniste's paper in light of the unfavorable referee reports; and why did the editor not send his investigating team to Benveniste's laboratory before publishing his paper, rather than afterwards (which, because of the failure to reproduce the results, would have prevented the whole uproar)?

Doury plausibly explains these puzzles in terms of the editor's fear to be compared to the inquisitors persecuting Galileo (p. 160; cf. Doury 1993, p. 129). To support this explanation, she mentions the fact that the editor of Nature confessed feeling such a fear, and she cites a secondary source (Pracontal 1990, pp. 13-14) to support this factual claim. Now, it turns out that it is possible to retrieve the editor's confession, from his own published words, in his final account that closed the journal's involvement in the affair. Here they are:

I should also have been more cautious when, having rejected the paper for what my colleagues hoped would be the last time, Dr. Benveniste telephoned indignantly to protest that Nature was proposing to suppress news of one of the greatest discoveries of the twentieth century. I forget whether he compared his dilemma to that of Galileo on that occasion or in a conversation during the later visit to Paris. [Maddox 1988a, p. 761]

Translating these words into the terminology of logic and argumentation theory, Maddox is saying that he wishes he could have been more skilled at the art of criticizing and responding to arguments of the type of the appeal to Galileo.

\section{Empirical elaboration: Other appeals to Galileo}

So far, a number of theses have emerged from this examination of Doury's account of the appeal to Galileo. She follows an approach to argumentation that is not only linguistic, empirical, and descriptive, but also mindful of dissensus (rather than con- 


\section{Finocchiaro}

sensus), of the audience as well as the two sides, and of the attempted refutations elicited by arguments. She applies this approach to a corpus or data base consisting of debates about the status of parasciences (such as astrology and parapsychology), as well as about the memory of water (Benveniste affair). She shows that the appeal to Galileo is a very common type of argument used by proponents of the parasciences, by defenders of Benveniste, and by critics in the Lysenko affair. She analyzes the appeal to Galileo as an argument from analogy, in which the arguer compares oneself to Galileo and one's opponents to the inquisitors, and in which one may support the analogy based on various specific alleged similarities; thus, she also clarifies that the appeal to Galileo is really an appeal to Galileo's trial. And she shows that appeals to Galileo are often subjected to attempted refutation in three ways: by undermining the analogy claim; by charging something like the fallacy of appeal to unpopularity; and by appealing to counter-examples in which the appeal to Galileo would lead to legitimizing many false and already discarded theories.

It should be obvious from my reconstruction that I find Doury's approach congenial and fruitful, although of course there is no reason to follow it literally or parrot it uncritically. Her data base is sufficiently substantial and rich that her claim about the existence and prevalence of the appeal to Galileo can be regarded as a robust empirical discovery; but of course this also means that the empirical presence of appeals to Galileo can be investigated much further. Her analysis of the appeal to Galileo as an argument from analogy is not only essentially correct, but also has great explanatory power, for it makes sense of much argumentation on both sides as being sub-argumentation designed to strengthen or to undermine the analogical premise by examining the presence of similarities or differences between the present case and Galileo's; but again this suggests and opens the door for discussions of the strength or weakness of the analogy based on historically informed knowledge of the details of Galileo's case. Similarly, there is not only empirical accuracy, but also theoretical and methodological suggestiveness and potential in her description of the two other ways in which appeals to Galileo are criticized; that is, by charging a fallacy of appeal to unpopularity, and by appealing to counter-examples.

In short, Doury's account is not only interesting, important, and insightful, but also fruitful and suggestive. However, although my reconstruction (in section 2 above) justifies the interpretive parts of the claims just made, the evaluative parts of 
these same claims are yet to be elaborated, let alone justified. To this task I now turn.

\subsection{Creationists and global-warming skeptics}

To begin with, besides the debates studied by Doury, there is another series of controversies in which the appeal to Galileo is also widespread. These are contexts where an individual or a small minority want to defend a claim that conflicts with the views of what appears to be the scientific establishment or the overwhelming majority of the scientific community. Important cases where this happens are the ongoing controversy over evolution and creation, and the recent controversy over global warming and climate change.

For example, there is a book entitled What is Creation Science?, in which the authors argue in favor of a creationist theory and against an evolutionary theory, in biology, geology, and cosmology. In a chapter entitled "The Fossil Evidence," among many other arguments, we find the following passage:

... creation is a scientific concept. It's based on testable hypotheses and stimulates research. When Galileo presented the evidence against Ptolemy's earth-centered view of astronomy, leaders of 'the establishment' refused to even look through his telescope. The leaders in those days were both churchmen and scientists who had, unfortunately, made the thinking of an early Egyptian astronomer an article of faith (a warning against making a particular theory an 'article of faith' in the 'establishment' today?). Today it's too often the evolutionist who hides behind thought-stifling ridicule and cliché (e.g., misinterpreted 'separation of church and state') and refuses to even 'look through the telescope' (or microscope!) at the evidence of creation.

If it was wrong in Galileo's day to suppress evidence, wrong of the Inquisition to ban books, and wrong at the Scopes trial to present only one view of origins, how can it be right (with hands covering eyes, ears, and mouth) to suppress the evidence of creation, to ban books and a major history-shaping system of thought from the classroom (and from the hearts and minds of young people), and to establish one view of origins as the official tax-supported 'state view'? ... [Morris and Parker 1987, pp. 175-77]

With regard to global warming and climate change, an important example of appeal to Galileo occurred during the Ameri- 
can presidential campaign for the 2012 election. The Republicans running for their party's nomination started their campaigns early, and they engaged in several debates as early as the summer of 2011. One of the contenders was the governor of the state of Texas, Rick Perry, and one of the debates was held on 7 September 2011. At one point, Gov. Perry was asked whether he believed in man-made climate change. He replied:

\begin{abstract}
Well, I do agree that the science is not settled on this. The idea that we would put Americans' economy at jeopardy based on scientific theory that's not settled yet, to me, is just nonsense, I mean ... just because you have a group of scientists that have stood up and said here is the fact. Galileo got outvoted for a spell. But the fact is, to put America's economic future in jeopardy, asking us to cut back in areas that would have monstrous economic impact on this country, is not good economics, and I will suggest to you is not necessarily good science. Find out what the science truly is before you start putting the American economy in jeopardy. ${ }^{3}$
\end{abstract}

The same controversy generated a more recent and even more memorable example of appeal to Galileo. This happened as a result of a speech delivered in Indonesia by the American secretary of state John Kerry on 16 February 2014. As many others have claimed before and since, Kerry (2014) claimed that the science is settled on the question of global warming and climate change. His remarks generated considerable discussion, which need not be examined here, except for one particular reaction. Some deniers of climate change suggested that the current talk about the settled science of global warming is like the seventeenth-century allegedly settled Ptolemaic science of the earth standing still at the center of the universe, and indeed reminiscent of the Inquisition's persecution of Galileo. Such an appeal to Galileo was cleverly expressed in a cartoon created and disseminated by cartoonist Chip Bok (Fig. 1): ${ }^{4}$

\footnotetext{
3 Cf.: http://www.nytimes.com/2011/09/08/us/politics/08republican-debatetext.html?pagewanted=all\&module $=$ Search $\&$ mabReward $=$ relbias $\% 3 \mathrm{As} \% 2 \mathrm{C}$ $\{\% 222 \% 22 \% 3 \mathrm{~A} \% 22 \mathrm{RI} \% 3 \mathrm{~A} 16 \% 22\} \& \mathrm{r}=0$; consulted on 19 November 2014. I have slightly edited this passage (as others have also done), to eliminate the usual features of spoken as contrasted to written language, such as repetitions, pauses, etc.

4 See: http://bokbluster.com/2014/02/23/settled-science/, consulted on 20 November 2014.
} 


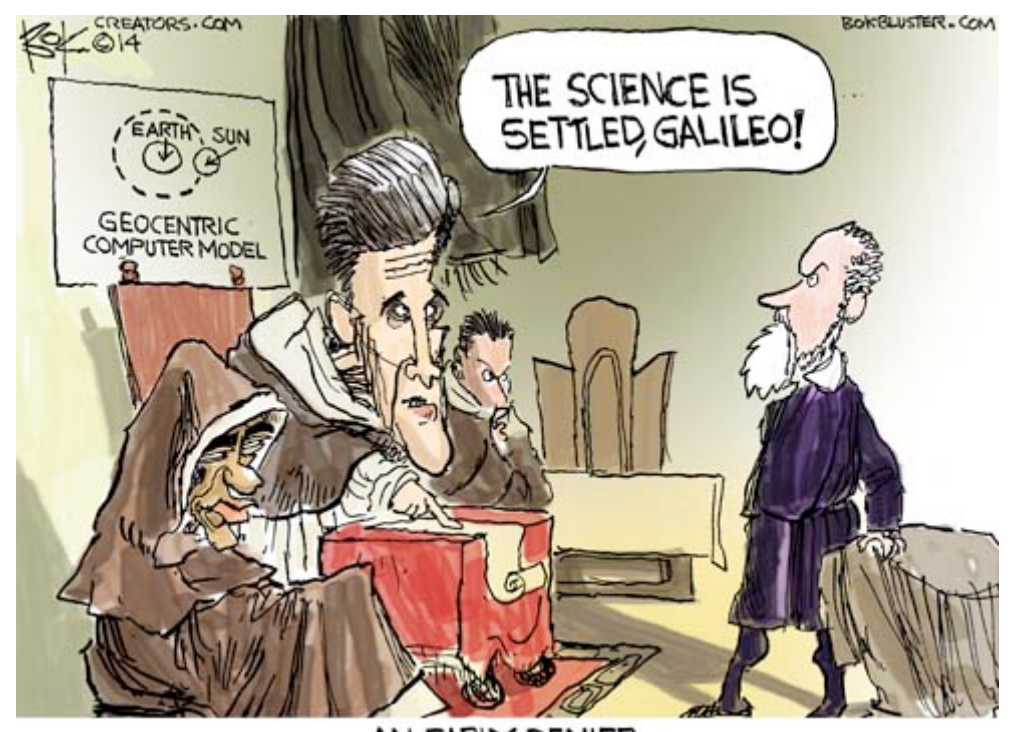

\section{AN EARLY DENIER}

Fig. 1 Cartoon in many newspapers in February 2014; cf. http://bokbluster.com/2014/02/23/settled-science/

Two points are worth mentioning about this cartoon. First, it should be obvious that the person confronting Galileo on the other side of the table has a face resembling John Kerry. Second, it is useful to point out that this image can obviously be seen as a variation or modification of a well-known painting by Cristiano Banti in the nineteenth century (Fig. 2):

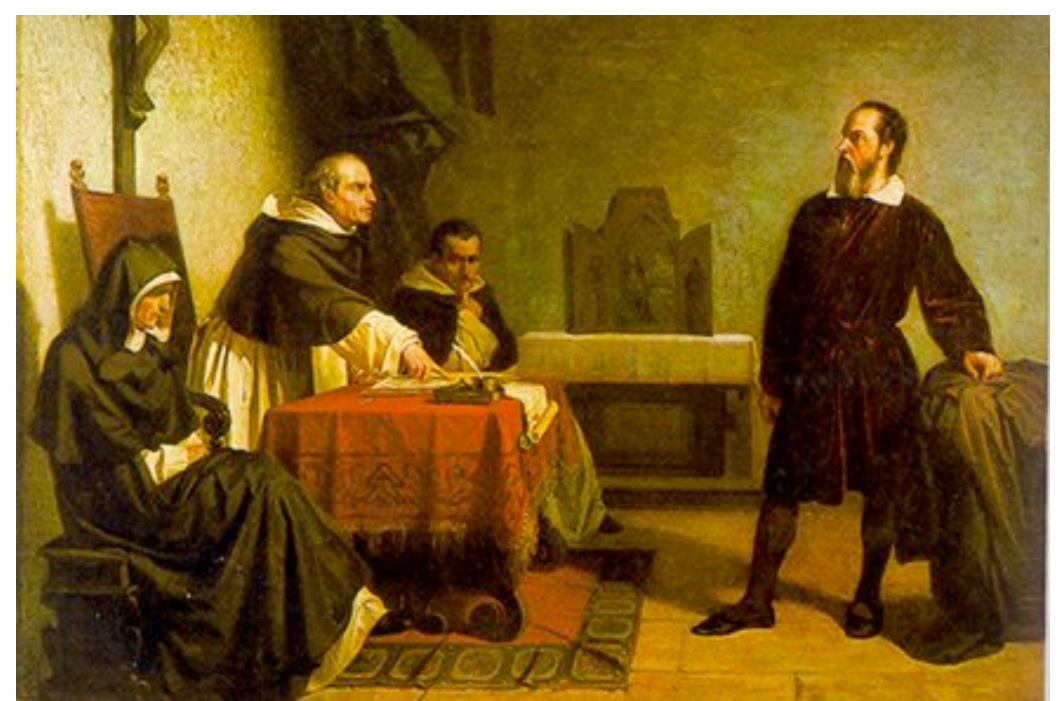

Fig. 2 Cristiano Banti (1857), "Galileo Facing the Roman Inquisition"

Of course, such appeals to Galileo raise many questions and provide material for many possible investigations. For example, the early-denier cartoon is so cryptic as an argument that 
some reconstruction would be desirable. However, the analogical character of its argumentation is relatively obvious; and equally obvious is the potential for analyzing the image with the full resources of the recent scholarship on visual argumentation (e.g., Groarke 1996, Blair 1996, Dove 2012), although the details of such an analysis might be challenging. Moreover, the argument embodied in the cartoon and suggested by Rick Perry obviously should not be accepted uncritically. To this end, the following considerations would provide a start (cf. Finocchiaro 1980, 1989, 2010).

Let us focus on the fact that some deniers compare themselves to Galileo insofar as, like him, they are denying what seems to be the majority opinion of the scientific community, and they compare their opponents to Galileo's inquisitors in the sense that both try to curtail freedom of thought and research. Here some distinctions are necessary. First, there are two main kinds of denials: one kind consists of merely negating what an opponent is asserting, another amounts to constructively elaborating an alternative to the opponent's view; the first might be labeled empty pro-forma denial, the second constructive contextual denial; we might even speak of unreasoned versus reasoned denial. Galileo's denial of the geostatic world system was clearly of the constructive, contextual, reasoned kind; but among the deniers of climate change only some are constructive deniers, whereas some are empty deniers; obviously the latter cannot compare themselves to Galileo, only the former can.

Additionally, with regard to Galileo's opponents, they too were of two main types. Certainly, some of his opponents were inquisitors and Church officials, who held some position of power or authority, but had little or no scientific knowledge of the relevant parts of astronomy, cosmology, and natural philosophy. However, other opponents were scientific peers whose own work and individual judgment in these fields led them to uphold various aspects of the traditional Ptolemaic world system. Now opposition and restrictions to Galileo on the part of the former may be deemed questionable or wrong, but opposition from the latter group seems legitimate and even necessary. Here, there is indeed an analogy to climate change; that is, interference by politicians to the reasoned denial of climate change looks like the Inquisition's persecution of Galileo, whereas scientists' reasoned criticism of deniers of global warming (even if this denial is itself reasoned) is quite proper.

In short, in this controversy, there is a tendency to misunderstand the difference between reasoned and unreasoned deni- 
al, and the difference between reasoned and unreasoned advocacy.

However, my main claim here is that the appeal to Galileo is much more common and widespread among advocates of minority opinions than one might think from Doury's evidence. That is, besides characterizing debates over parasciences and the Benveniste and Lysenko affairs, the appeal to Galileo also characterizes the creation vs. evolution controversy and the controversy over global warming and climate change. However, even from such an empirical perspective, various points deserve attention. One is that there are probably cultural and national differences with regard to how frequently such appeals occur and how plausible they are perceived to be; for example, although it is not exactly true that creationist appeals to Galileo are a uniquely American phenomenon (cf. Numbers 2009), they are certainly more common in the United States than in France.

Another important point is that appeals to Galileo by climate-change skeptics or deniers are much more common than appeals by creationists. This is unsurprising, given the greater urgency and practical relevance of climate change. Indeed the amount of discussion on Galileo and climate change and global warming is so great that this topic alone deserves separate, sustained, and systematic study. Here, I shall limit myself to just mentioning two additional examples.

In 2010, a group of French scientists sent an open letter to a number of French authorities, such as the government Minister of Research, the president of the Academy of Sciences, and the director of the National Council of Scientific Research; eventually the letter was signed by as many as 500 scientists. The letter was asking these officials and these institutions to intervene to protect the integrity of climate research and the reputation of scientists from criticism they had received; in particular, two critics were mentioned, Claude Allègre and Vincent Courtillot, who had published books claiming to expose various errors, irregularities, and improprieties committed in climate research. This letter elicited considerable discussion, much of it negative. In particular, one Benoit Rittaud wrote a public rebuttal, arguing that the letter's request was inappropriate because it was appealing to political authorities to settle or arbitrate a scientific disagreement; on the other hand, if a particular scientist felt personally slandered, then the proper recourse would be to sue in a law court, which would reach a judgment on questions of personal harm or injury, but not on the truthfulness or correctness of a scientific opinion. 
This particular controversy led a blogger named Laurent Berthod to post an article entitled "Galileo appeals to the Holy Office against his bad colleagues" (Berthod 2010). He reproduced verbatim the original letter and Rittaud's rebuttal; gave references to a few other events, documents, and websites; and added a brief, one-paragraph commentary explaining the title he had given to his blog. Berthod suggests that the appeal of the 500 scientists is as absurd as it would have been if Galileo had appealed to the Inquisition for support in the Copernican controversy. Berthod's own argument is an appeal to Galileo, in the sense that he is reaching a conclusion critical of some proponents of climate change, based on an analogy between their behavior and Galileo's trial. In this case, the precedent or reference analogue is not the actual behavior of the Inquisition or of Galileo, but rather an hypothetical or imagined behavior of Galileo; and then the other premise is a judgment that such Galilean behavior would have been self-contradictory, incoherent, and selfdefeating. Such an argument is much more complex than the previous examples, but is also an instance of appeal to Galileo.

Finally, it should be mentioned that in Australia an organization has been formed aimed to criticize the consensus that seems to have emerged among advocates of global warming and climate change. This organization calls itself the "Galileo Movement," because its founders draw their inspiration from Galileo's struggle for the Copernican world view and for freedom of thought. In their own words:

The Galileo Movement's co-founders are retirees Case Smit and John Smeed. Their business backgrounds are in science and engineering-science's real-world application. Their experience is in environmental protection and ensuring air quality. At first they simply accepted politicians' claims of global warming blamed on human production of carbon dioxide $\left(\mathrm{CO}_{2}\right)$. When things didn't add up, they each separately investigated. Stunned, they discovered what many people are now discovering: climate claims by some scientists and politicians contradict observed facts ... Galileo Galilei (1564 to 1642) is a 'father of science' ... The 'settled science' and frightened consensus of his peers was that the sun orbited Earth. Galileo proved them wrong. He then stood up to the entrenched, dogmatic religious and state beliefs suppressing the truth ... Taking his name, we honour his integrity and courage in championing freedom and protecting science. He replaced religious doctrine with solid observable data. His outspoken defence of truth is a rallying cry to all people 
valuing freedom and objective understanding of the world. ${ }^{5}$

\subsection{Advocates of 'settled science'}

My next claim is that appeals to Galileo are common not only among advocates of minority opinions, but also among proponents of establishment views or dominant opinions in science. A good example of this is an editorial column in Time magazine by science journalist Jeffrey Kluger (2014), published on 17 February 2014, one day after secretary Kerry delivered his speech in Indonesia.

In his speech, Kerry had compared the scientific certainty of climate change to such scientific facts as the freezing and the boiling points of water and the law of gravity, and he had also compared the deniers of climate change to the flat-earth believers. However, he had not even mentioned Galileo. In his editorial, Kluger echoed that theme in a more incisive way by comparing the proponents of climate change to Galileo and its opponents to believers in a motionless earth at the center of the universe. In fact, Kluger's column was revealingly entitled "The Science of Stupid: Galileo is Rolling Over in His Grave." This theme may be seen from the following passages:

So here's a fine howdy-do for Galileo Galilei: Exactly one day-one flipping day-after the great man's 450th birthday, on Feb. 15, 2014, a study by the National Science Foundation (NSF) revealed that one in four Americans does not know that the Earth orbits the Sun ... the European Union fared even worse, with $36 \%$ flunking the heliocentrism part of the science test. It's a reassuring truth of human history that wisdom is eternal. Our greatest accomplishments and insights in art, science, technology, philosophy, theology, medicine and government are timeless - things that once known can never truly be unknown. But it's an equally hard truth that stupid is forever too. The flat-earthers have always been with us, as have the believers in phrenology and alchemy and eugenics and sorcery, and, more recently and perniciously, the climate change deniers and the vaccines-cause-autism ninnies. Sometimes it's greed and political calculation at work: If we call climate change a hoax, we keep the riches flowing to the fossil fuel industry ... Galileo's perse-

\footnotetext{
${ }^{5}$ At: http://www.galileomovement.com.au/who_we_are.php\#B, consulted on 20 January 2015; cf. Fischer 2011.
} 


\section{Finocchiaro}

cutors were the fathers of the Catholic Church, holding fast to a Bible that described the Earth as fixed and unmovable and the sun as rising and setting and returning to its place each day. The people who deny evolution today aren't in the field, collecting the bones and offering reasoned alternatives to what Darwin discovered. They too know what they know because the Bible says - or seems to say-it's true ... religious fundamentalists who defy inquisitiveness, defy reason, demanding a literal interpretation of Scripture that includes a great flood and a 6,000 year old world and a planet full of fossils and billionsyear-old rocks that are put there merely to test our faith ... The world is 4.5 billion years old. Full stop. The Earth does revolve around the Sun-period. On these matters, the modern day fundamentalists are-how best to put this?-wrong. When the Catholic Church as long ago as 1758 lifted its ban on teaching the sun-centered solar system and in 1992 formally acknowledged error in its treatment of Galileo, the very guardians of Scripture themselves were acknowledging that simply because a verse is written in a book does not make it so. To insist otherwise is to fight a rearguard action, one that holds entire societies back. [Kluger 2014]

Although it is obvious that there is an appeal to Galileo here, it is not clear that it is the same kind of appeal discussed so far, studied by Doury, and amounting to an argument from analogy. Actually, it is not easy to reconstruct Kluger's argument.

We could take his key claim to be that $(\mathrm{K})$ "Galileo is rolling over in his grave" on account of such things as (K.1a) current ignorance of heliocentrism, (K.1b) current creationist rejections of evolution, and (K.1c) currents denials of climate change; that is, Galileo would disapprove of such developments. Presumably, this (three-fold) key claim seems to be supported as follows: because (K.1a.1) "the Earth does revolve around the Sun-period," and (K.1a.2) Galileo spent his life confirming it; because (K.1b.1) creationist rejections of evolution stem from the principle that the Bible is a scientific authority, and (K.1b.2) Galileo spent his life arguing against this principle; and because (K.1c.1) denials of climate change are based on "greed and political calculation," and [perhaps] (K.1c2) Galileo taught us that the search for truth should be pursued independently of base practical motivations. And in turn, from the key claim, Kluger is implicitly inferring the final conclusion that $\left(\mathrm{K}^{\prime}\right)$ we too should disapprove of such developments; that is, we should support better scientific education about heliocentrism, evolution, and cli- 
mate change.

This last step ( $\mathrm{K}$ to $\mathrm{K}^{\prime}$ ) of the over-all argument would basically be an argument from authority; and it would have considerable inferential strength or plausibility, given that the reliability of Galileo's authority in science could hardly be questioned. With regard to the step supporting the key claim $(\mathrm{K})$, it does not instantiate any simple or obvious argument form. But, at a deeper level, the three strands together seem to presuppose a comparison, similarity, or analogy among the three situations to which they refer. Now, this presupposition fails to make several important distinctions and compares or confuses situations that are dissimilar; that is, it overlooks the differences stemming from the dynamics or historicity of scientific knowledge, and from the epistemological context or status of scientific theorizing. The key distinctions are the following (cf. Finocchiaro 1980, 1989, 2010).

First, there is the disparity between the question of the earth's motion in Galileo's time, which was an unsettled and controversial issue, and the question of the earth's roundness at that same time, which was a non-issue at that time because it had been settled by the ancient Greeks. Second, there is the dissimilarity between the issue of the earth's motion in Galileo's time and the question of the earth's motion in the twenty-first century, which is now a non-issue, having been settled in the intervening four centuries. Thus, although today both the earth's roundness and the earth's motion are settled, terrestrial roundness is more settled than terrestrial motion; furthermore, today terrestrial motion is more settled than biological evolution, even though the latter is more settled than global climate change; and in Galileo's time the earth's roundness was already settled, but the earth's motion was not yet settled, despite his epoch-making and robust confirmation.

These differences imply that the notion of "settled science" is a matter of degree, such that scientific claims are susceptible of being more or less "settled." However, such differences do not imply that science is never settled and that the idea of settled science is a myth, as some writers have argued (Krauthammer 2014). They imply rather that the notion of settledness is a gradual non-discrete concept.

These evaluative considerations, and the earlier interpretive puzzles, suggest that more work is needed on this topic. However, they do not refute my main present claim, to the effect that appeals to Galileo are common among the advocates of dominant scientific opinions or defenders of "settled science," 


\section{Finocchiaro}

and not merely among the partisans of minority views; both sides of a large range of controversies make appeals to Galileo. On the other hand, these considerations suggest that some appeals to Galileo are primarily arguments from authority rather that arguments from analogy, and that they presuppose analogies at a deeper implicit level rather than explicitly appealing to them.

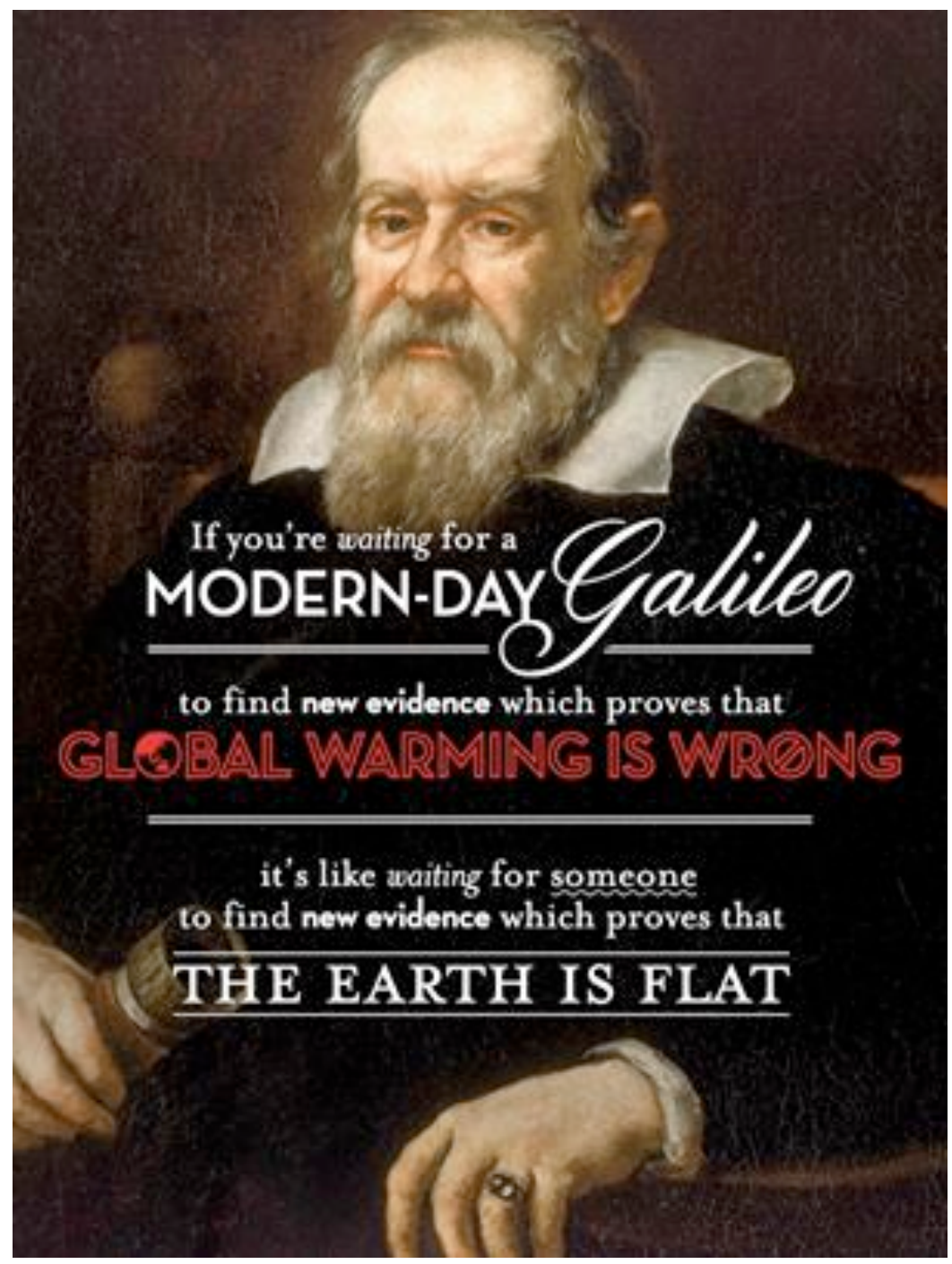

Fig. 3. Image created by Jarren Nylund

(http://www.skepticalscience.com/climate-skeptics-are-like-galileointermediate.htm)

To strengthen my main present claim, it is useful to mention a simpler example of appeal to Galileo by advocates of 
global warming. This appeal is made by a group that calls itself "Skeptical Science" and describes itself as aiming at "getting skeptical about global warming skepticism." Referring explicitly to Governor Perry's comparison of global-warming skeptics to Galileo, they formulate a lengthy and clear counterargument, which they succinctly summarize as follows: "the comparison is exactly backwards. Modern scientists follow the evidence-based scientific method that Galileo pioneered. Skeptics who oppose scientific findings that threaten their world view are far closer to Galileo's belief-based critics in the Catholic Church." And they even give a visual aid, by encapsulating their argument in the image on the previous page, (Fig. 3), created by Jarren Nylund.

\subsection{Einstein, Newton, etc.}

Another subtype of appeal to Galileo is more important. It occurs in the context of scientific research when a scientist is engaged in methodological or epistemological reflection stemming from a concrete scientific problem. In such cases, scientists are trying to decide how to proceed and how to justify the procedure they choose. They often do so by appealing to abstractly formulated methodological principles or to historical precedents of methodological models. Few cases in the history of science possess the drawing, inspirational, and instructive power of Galileo. And this applies not only, and not even primarily, to the potential lessons derivable from his trial and affair with the Inquisition, but mostly to the lessons derivable from his scientific discoveries and inventions, and his other contributions to the foundations of modern science. Thus, it is not surprising, but rather has become a commonplace, that scientists regard him not only as one of several founders of modern science, but also single him out as the "Father of Modern Science" (Einstein 1954, p. 271; Hawking 1988, p. 179).

An example from Einstein will illustrate my claim. It occurs in an essay which he wrote in 1953 as the Foreword to the English translation by Stillman Drake of Galileo's Dialogue Concerning the Two Chief World Systems, Ptolemaic and Copernican, published by the University of California Press. Einstein claims that the ancient geostatic thesis was based on the hypothesis of the existence of an abstract center of the universe, and that this hypothesis was accepted because it provided an ex-

6 See http://www.skepticalscience.com/climate-skeptics-are-like-galileointermediate.htm, consulted on 16 January 2015. 
planation of the fall of heavy bodies. Then he claims that Galileo rejected the hypothesis of the existence of an abstract universal center on the grounds that "although it accounts for the spherical shape of the earth it does not explain the spherical shape of the other heavenly bodies" (Einstein 1953, p. xiii). Einstein claims next that there is an analogy between this Galilean argument and the rejection by his own theory of general relativity of "the hypothesis of an inertial system for the explanation of the inertial behavior of matter" (Einstein 1953, p. xiii). The analogy is that both the Galilean and the relativistic criticism object to the postulation of an entity which has the very peculiar property of affecting the behavior of real objects without being affected by them, thus lacking the same kind of reality that matter or fields do. Finally, he asserts that such entities are "repugnant to the scientific instinct" (Einstein 1953, p. xiii).

Einstein's remarks can be reconstructed as amounting to the following argument (cf. Finocchiaro 1980, pp. 67, 97; 2014b, pp. 314-16). (E.1.1) In the Dialogue, Galileo rejected the hypothesis of the existence of a center of the universe as providing the explanation of the fall of heavy bodies. (E.1.2) In modern relativistic physics, the hypothesis of an inertial system as providing the explanation of the inertial behavior of matter is analogous to the one rejected in Galileo's Dialogue; for both hypotheses introduce a conceptual object which (E.1.2a) does not have the same kind of reality that matter and fields do, and which (E.1.2b) affects the behavior of real objects, without being affected by them. Therefore, (E.1) the hypothesis of an inertial system is as unscientific as the one about a center of the universe rejected by Galileo. Therefore, (E) the hypothesis of an inertial system should be rejected.

Here Einstein is referring to Galileo's critique of an Aristotelian argument for geocentrism that was based on the natural motion of terrestrial bodies (Galilei 1967, pp. 31-38; cf. Finocchiaro 2015, pp. 31-32). Einstein's first premise (E.1.1) is attributing to Galileo the criticism that this Aristotelian argument assumes that a center of the universe exists; and although such a criticism is not explicit in the text, it is certainly plausible to make the attribution, and to say that it is implicit. Then Einstein is assuming that Galileo is an appropriate scientific model, and goes on to detect an analogy between the situation he himself faces and the one faced by Galileo. And Einstein's conclusion is that he can do today something analogous to what Galileo did.

In this particular case, the analogy is not merely asserted, but also justified, and the justification is based primarily on an 
appeal to a methodological principle under which both situations can be subsumed. In Einstein's words, this principle says that the introduction of an entity such that "it determines the behavior of real objects, but it is in no way affected by them ... is repugnant to the scientific instinct" (Einstein 1953, p. xiii). And this principle too happens to have an analogue in Galileo. In fact, in a related passage, Galileo explicitly applies the same principle to the case (in the Aristotelian world view) of the heavenly bodies (made of aether) that affect terrestrial bodies (made of earth, water, air, and fire) without being affected by them. With his inimitable mixture of scientific intuition, methodological acumen, rhetorical sensibility, and poetical imagination, Galileo remarks that "I do not see how the influence of the moon or sun in causing generations on the earth would differ from placing a marble statue beside a woman and expecting children from such a union" (Galilei 1967, p. 60).

Einstein's appeal to Galileo is not an isolated case. In fact, such appeals started at least as early as 1687, when Isaac Newton made some Galilean references in his Mathematical Principles of Natural Philosophy (Newton 1999, p. 424; cf. Finocchiaro 1980, pp. 96-97). These references are partly substantive in the sense of describing Galileo's main discoveries in physics, involving the laws of falling bodies, pendulum, and parabolic path of projectiles. But they are also partly methodological, in the sense of attributing to Galileo a derivation of these laws from the basic laws of motion, such as inertia, force, and composition of motion.

Thus, Galileo's work can be used, and has been used, by working scientists as a model to follow in their own scientific investigations. Such modeling does not consist of a simple process of mechanically following easy recipes found in, or attributable to, his work; such a process would amount to simplemindedness and oversimplification. Instead, the methodological utilization of Galileo's work involves the critical comparison and contrast of the scientific problem one is facing with some scientific problem faced by Galileo, and such a comparisoncontrast is to be done both in terms of the concrete substantive details and in terms of relevant methodological principles. In short, here we have an exercise in the construction and evaluation of arguments from analogy, formally and informally analogous to the appeals to Galileo examined by Doury in the debates about parasciences. 


\subsection{Hume, Kant, etc.}

As might be expected by now, the utilization of Galileo as a methodological model, by means of arguments from analogy, is not limited to the natural sciences. It also occurs in philosophy. An important example is found in David Hume's Dialogues Concerning Natural Religion, first published in 1779.

Hume's Dialogues is a book that discusses arguments for and against the existence of God, elaborating a skeptical or agnostic position to the effect that there are no good reasons or evidence in favor, but there are some strong objections against it (cf. Hume 1947; Finocchiaro 2013, pp. 201-18). The potential for exploiting Galilean lessons is obvious once we realize that one of Galileo's principal works is the Dialogue Concerning the Two Chief World Systems, Ptolemaic and Copernican, first published in 1632; and that Galileo's Dialogue is a critical examination of the arguments for and against the motion of the earth, showing that the pro arguments are much stronger than the con arguments, and concluding that the Copernican hypothesis is probably true (cf. Galilei 1967; Finocchiaro 2014b).

However, Hume makes only one appeal to Galileo. At one point, at the beginning of the discussion, Hume raises the issue whether the existence of God can be proved empirically, by some kind of causal argument. One of the speakers, the agnostic Philo, claims that in order to prove from experience that an orderly universe must arise from an intelligent divine cause we would need sensory experience of the origin of universes, which is obviously impossible.

Another interlocutor, the theist Cleanthes, replies that such a proof of the existence of God is no more impossible than it is to prove the earth's motion from experience; thus, if Philo's skeptical objection were effective in the theological dispute, it would have been effective in the Copernican controversy. In his own words, "to prove by experience the origin of the universe from mind is not more contrary to common speech than to prove the motion of the earth from the same principle. And a caviller might raise all the same objections to the Copernican system which you have urged against my reasonings. Have you other earths, might he say, which you have seen to move?" (Hume 1947, p. 150 [Dialogues, pt. ii, paragr. 25]).

Philo replies that the two situations are not analogous, because, unlike the situation in theology, in the Copernican case it turned out to be possible to acquire the required empirical evidence of the motion of other earth-like bodies. To support this 
last claim, he advances the following interpretation of Galileo's Dialogue: that Galileo first refuted the earth-heaven dichotomy, by proving empirically the similarity between the earth and the heavenly bodies; then he proved empirically that the moon, sun, and planets moved (for example, the moon and sun with axial rotation, the planets with heliocentric revolution); and so, by analogy he concluded that the earth also moves. In Philo's words:

if we peruse Galileo's famous Dialogues concerning the system of the world, we shall find that that great genius, one of the sublimest that ever existed, first bent all his endeavours to prove that there was no foundation for the distinction commonly made between elementary and celestial substances. The schools, proceeding from the illusions of sense, had carried this distinction very far; and had established the latter substances to be ingenerable, incorruptible, unalterable, impassible; and had assigned all the opposite qualities to the former. But Galileo, beginning with the moon, proved its similarity in every particular to the earth: its convex figure, its natural darkness when not illuminated, its density, its distinction into solid and liquid, the variations of its phases, the mutual illuminations of the earth and moon, their mutual eclipses, the inequalities of the lunar surface, etc. After many instances of this kind, with regard to all the planets, men plainly saw that these bodies became proper objects of experience, and that the similarity of their nature enabled us to extend the same arguments and phenomena from one to the other. [Hume 1947, 151 (Dialogues, pt. ii, paragr. 27)]

Hume gives no specific references, but it is not difficult to find the Galilean passages - the analogue(s) of this appeal to Galileo. The whole "First Day" (out of four) of Galileo's Dialogue contains objections to the Aristotelian dichotomy between earth and heaven, and arguments for the similarity between the earth and the heavenly bodies (Galilei 1967, pp. 9-105; Finocchiaro 2014b, pp. 51-89). Less obvious, but equally pertinent, is a passage in the "Second Day," where we find what might be called an argument from the negative correlation between luminosity and mobility. There, Galileo argues that the earth probably moves because, like the moon and the planets, it is dark or devoid of intrinsic luminosity, and these bodies move; whereas the sun as well as the fixed stars, being intrinsically luminous, are devoid of (geocentric) motion (Galilei 1967, pp. 264-75; Fi- 
nocchiaro 2014b, pp. 159-64).

It should be noted that here Hume (who seems to be siding with Philo) is drawing a negative lesson from Galileo: that is, with regard to the existence of God one cannot do what Galileo did with regard to the motion of the earth, namely justify the latter on the basis of empirical evidence about the motion of other "earths," because no empirical evidence about other universes being caused by intelligent designers is, or can be, available. With this qualification, Hume's interpretation has some basis in the Galilean text, and so the lesson he draws (albeit a negative one) has some probative weight.

On the other hand, Hume's reading of Galileo is not completely accurate. One inaccuracy is that he treats the "distinction into solid and liquid" as a similarity between the earth and the moon; whereas Galileo argues explicitly that there is probably no water on the moon, and so this absence generates one difference between the two bodies (Galilei 1967, 98-105; Finocchiaro 2014b, pp. 86-89). More importantly, Hume (through Philo) makes it sound as if the geokinetic argument from the negative correlation between luminosity and mobility were stronger and more central than it is; in fact, it is rather weak (although it has some plausibility), and its importance is secondary. Even more crucially, Hume seems to presuppose that all empirical arguments would have to be arguments from analogy, like this one from the negative correlation between luminosity and mobility, which is also a positive correlation (and hence an analogy) between darkness and mobility, or between luminosity and rest. However, of the many pro-Copernican arguments in Galileo's Dialogue, only one other has the same type of analogical empirical basis; this is the argument from the heliocentrism of planetary revolutions (Galilei 1967, pp. 318-27; Finocchiaro 2014b, pp. 173-77). All the other geokinetic arguments are essentially inferences to the best explanation, which are indeed empirical, but depend on observed phenomena that cannot be explained equally well by the earth's rest; such arguments are not based on the observation of the motion of other "earths." Thus, Hume could perhaps be criticized for a superficial reading of Galileo's Dialogue.

These points could be pursued at greater length and in greater depth; but that cannot be done here. For our main point in the present context was to illustrate and substantiate our claim that it is possible to utilize Galileo's works as a model to follow in our own investigations, even when they do not pertain to questions of natural science. Moreover, as Doury points out in her account 
of the debates over parasciences, such appeals to Galileo, being arguments from analogy, have not only the strengths but also the weakness of analogical arguments. That is, the analogy can often be questioned, not only by questioning the myths or alleged facts of Galileo's trial (as in Doury's cases), but also by questioning the similarities between the logic or methodology of the arguer's current situation and the logic and methodology of Galileo's situation (for cases like those of Hume and even Einstein). Here I have suggested some ways of questioning Hume's appeal to Galileo.

However, to end on a more positive note, Hume's example is not an isolated case of philosophers' appeals to Galileo. Another classic example deserves at least mention. ${ }^{7}$ It occurs in the Preface to the second edition (published in 1787) of Kant's Critique of Pure Reason, where he claims to want to bring about in the field of metaphysics a revolution like that of Galileo in experimental physics:

When Galileo caused balls, the weights of which he had himself previously determined, to roll down an inclined plane; when Torricelli ... when Stahl ... a light broke upon all students of nature. They learned that reason has insight only into that which it produces after a plan of its own, and that it must not allow itself to be kept, as it were, in nature's leading-strings, but must itself show the way with principles of judgment based upon fixed laws, constraining nature to give answers to questions of reason's own determining ... Their success should incline us, at least by way of experiment, to imitate their procedure, so far as the analogy which, as species of rational knowledge, they bear to metaphysics may permit. Hitherto it has been assumed that all knowledge must conform to objects. But all attempts to extend our knowledge of objects by establishing something in regard to them $a$ priori, by means of concepts, have, on this assumption, ended in failure. We must therefore make trial whether we may not have more success in the tasks of metaphysics, if we suppose that objects must conform to our knowledge. [Kant 1965, pp. 20-22 (Bxii-Bxvi)]

Here, the analogical nature of the appeal to Galileo is explicitly indicated by Kant himself, and so the interpretation or recon-

\footnotetext{
${ }^{7}$ Besides the examples of Hume and Kant, a third one deserves at least a brief footnote: José Ortega y Gasset (1956; 1958, pp. 11-20), on the subject of philosophy of history and cultural history; cf. Finocchiaro 1980, pp. xviiixix.
} 
struction of Kant's argument would be a relatively easy task. However, one complication (at the interpretive level) would be the fact that, as is well known, he also makes an appeal to Copernicus and the Copernican revolution, as involving a change from the viewpoint of attributing motion to the observed heavenly bodies to attributing it instead to the observer on earth; I have omitted this complication from my quotation, but my hunch is that Kant's appeal to Copernicus is "analogous" to his appeal to Galileo. On the other hand, the evaluation of Kant's appeal(s) would be more challenging, although, again, we obviously know already that the main issue would be the strength or weakness of the analogy.

\section{Theoretical elaboration: Varieties of Galilean appeals and of criticism}

At this point, one is tempted to try to conceptualize and interpret the appeal to Galileo as an "argumentation scheme," in accordance with the various recent accounts that have used this notion. Then the appeal to Galileo would constitute a previously uncatalogued addition to, for example, the some sixty such schemes and the many more versions or subtypes that have been discussed by Walton, Reed, and Macagno (2008). But I shall leave that task as an exercise for the interested reader.

One is also tempted at this point to try to apply various ideas that have been elaborated in the theoretical literature on the argument from analogy. For example, it certainly would be valuable to inquire whether the appeal to Galileo, as an argument from analogy, is "descriptive" or "normative" (Garssen 2009, Eemeren and Garssen 2014); whether it is "qualitative" or "quantitative" (Bermejo-Luque 2014); whether it is "figurative" or not (Waller 2001, Garssen 2009); whether it is in accordance with "scheme 1" or "scheme 2" (Walton 2014); etc. However, my own approach is more empirically and historically oriented, more down to earth, so to speak. That is, before discussing or resolving such issues, which strike me as excessively theoretical in the present context, there are what I feel are more basic questions that need to be examined about the empirical material presented. This does not mean that the examination which I am about to undertake is conducted with a tabula rasa, or is not itself theory-laden; indeed, as the title of this section suggests, my own elaboration is itself a "theoretical" one, however low-level.

Similarly, the appeal to Galileo could be viewed from the 
perspective of Doury's (2009) own approach to the typology of argument schemes in general, and of her four-fold typology of comparative arguments in particular; and that might be a challenging problem for her to tackle next. However, again, here I shall proceed to formulate, clarify, and evaluate a number of (perhaps more basic) conclusions, issues, and other projects, in line with my own approach and as suggested by the preceding considerations.

Finally, and less controversially, one could easily show, I believe, that the appeal to Galileo is an "inductive," and not an "a priori," argument from analogy, in accordance with a widely discussed distinction (Govier 1989, Guarini 2004, BermejoLuque 2012). Indeed, some of the considerations already made above and to be made below may be taken as a demonstration of this particular thesis.

\subsection{Ground-level vs. meta-level "appeals"}

To begin with, it may be useful to distinguish the kind of appeal to Galileo discovered by Doury and elaborated here from a related enterprise that has been practiced for some time by at least one scholar in logic and argumentation theory. The related but distinct enterprise to which I am referring is the utilization of Galileo's argumentative practice (but also his life and scientific work) as a corpus or data base in the historical, empirical approach to logic and argumentation theory. In this other enterprise, the context is theoretical: one aims to formulate, clarify, test, and justify various concepts and principles for the interpretation, evaluation, and construction of reasoning and arguments in general; and in pursuing this goal one uses empirical and historical evidence consisting of Galileo's reasoning and arguments, and also to some extent the reasoning and argumentation of his interlocutors (cf. Finocchiaro 1980, 2005, 2010, 2013).

Let us look at some illustrations of conclusions reached in this other enterprise. Sometimes such conclusions are rather unpretentious and uncomplicated. For example, apropos of the concept of conductive argument, an arrestingly beautiful illustration is provided by the whole main argument in Galileo's Dialogue. And with regard to the concept of petitio principii or begging the question, some highly incisive examples are found in Galileo's critique of the geostatic argument from vertical fall. But sometimes the conclusions yielded by this enterprise are quite ambitious and wide-ranging; for example, that so-called fallacies (so-called in textbooks) are typically either non- 


\section{Finocchiaro}

fallacious arguments, or non-arguments, or inaccurate reconstructions of the originals; but that many arguments can be criticized as fallacious in various identifiable ways. And sometimes the conclusions are intermediate in scope; for example, that one of the most effective ways of criticizing arguments and reasoning is to engage in ad hominem argument in the seventeenth century meaning of this term, namely to derive a conclusion unacceptable to opponents from premises accepted by them, but not necessarily by the arguer. ${ }^{8}$

However, in Doury's kind of appeal to Galileo one is defending such claims as that astrological considerations can predict human behavior; that some human beings have parapsychological powers; that (as in the Benveniste affair) water can acquire from antigens previously dissolved in it, but no longer contained there, the ability to produce the same allergic reaction as those antigens; that creationism is a viable alternative to evolution; and that it is legitimate to deny the current scientific consensus about global warming and climate change.

One might say that in the appeal to Galileo the context is one of ground-level argumentation, whereas in the utilization of Galilean evidence in accordance with the historical, empirical approach to the theory of argument, the context is one of metaargumentation. Here, as a first approximation, groundargumentation is argumentation about physical phenomena, historical events, or human actions, whereas meta-argumentation is argumentation about arguments (cf. Finocchiaro 2013). As long as one does not misinterpret the distinction between ground- and meta-argumentation as an absolute one, this distinction may be helpful to conceptualize the difference between the appeal to Galileo and the theoretical utilization of Galilean evidence. However, there are other aspects of the latter difference. It is perhaps even more important to realize that whereas appeals to Galileo are (as Doury correctly points out) basically arguments from analogy, the arguments used by the logical theorist utilizing Galilean evidence are mostly inductive generalizations and inferences to the best explanation.

On the other hand, another subtle twist to this particular point should not be missed. Doury's reflections on the appeal to Galileo, as well as those in the present essay, are in the context of logical theorizing and meta-argumentation.

\footnotetext{
${ }^{8}$ Collecting and combining the references to the five examples mentioned in this paragraph, cf. respectively Finocchiaro 2013, pp. 152-57; 2013, pp. 21941 ; 2005, pp. 16, 109-27; 2005, pp. 16, 128-47; and 2005, pp. 16, 65-91, $277-$ 91, 329-39.
} 


\subsection{Galileo's trial vs. Galileo's methodology}

A second important distinction to be clarified is that between the appeal to Galileo as discussed by Doury and in parts of the present essay, and the appeal to Galileo as practiced by thinkers such as Einstein, Newton, Hume, and Kant and elaborated in other parts of the present essay. I believe the relationship between the two is that the appeal to Galileo à la Doury is a special case of the Einstein-Hume kind of appeal to Galileo, although of course both are arguments from analogy.

To see why, recall that, despite the substantive and topical differences between Einstein's and Hume's reflections, they are both appealing to Galileo's methodological practice and methodological reflections, comparing their own respective situations to some particular situation faced by Galileo, and concluding that they are justified in following the same approach or procedure. In Einstein's case, the analogy was the similarity between the unscientific character of two situations: for Galileo, having the heavenly bodies cause changes in terrestrial bodies without themselves undergoing any change; and for Einstein, having matter and fields be affected by an inertial frame of reference without the latter being affected by them. In Hume's case, the analogy was between the manner in which Galileo (allegedly) confirmed the motion of the earth and the manner in which Hume (at one point) proposes justifying the divine origin of the universe: in Galileo's case, one had to confirm the similarity between the earth and other heavenly bodies as well as the motion of those heavenly bodies; in Hume's case, one would have to confirm the similarity between this universe and other universes as well as the divine (or at least the intelligent-design) origin of those other universes. When Hume later points out that that proposal cannot be carried out, and hence that the divine origin of the universe cannot be proved from experience, Hume is assuming the analogy.

On the other hand, in the appeals to Galileo by proponents of the parasciences, they are appealing to Galileo's methodological practice and reflection, but usually only in the context of his trial and struggle with the Inquisition. This struggle does indeed embody methodological lessons that can be exploited, in the sense that Galileo's situation can be used as a model with which one can compare oneself, in deciding what do to or in determining what is true or likely to be true.

Thus, the difference is that whereas scientists (and some philosophers) appeal to Galileo's methodology in all sorts of 
situations, parascientists typically appeal to Galileo's trial, in the sense of the methodology embodied in the trial. They may be both called appeals to Galileo, even though the appeal to Galileo's methodology is a more general case, and the appeal to Galileo's trial is a more particular case.

\subsection{Evaluation vs. description; criticism vs. refutation}

I have already said that the appeal to Galileo (in both of its versions) is essentially an argument from analogy, and in this I am following Doury's interpretation. Another aspect of such argumentation also emerges from her account, but it is worth stressing explicitly. Such appeals are usually more complex than the single step reducible to the following scheme: $\mathrm{a}$ and $\mathrm{b}$ are analogous; $\mathrm{X}$ is true of $\mathrm{a}$; so, $\mathrm{X}$ is true of $\mathrm{b}$. They often include a second step supporting the judgment of analogy (the first premise in this scheme); such a step is usually an inductive generalization. And we have also seen that, as Doury points out, the most common attempt to refute an appeal to Galileo is to question the judgment of analogy, by pointing out differences that weaken the analogy or destroy it by justifying a disanalogy. Thus, at the interpretive level, one minor addition to Doury's account is to stress such complexity, namely the two-step character of the argumentation in an appeal to Galileo.

Another minor addition is this. Doury's analysis and examples suggest that the discussion of the strength or weakness of the analogy is usually based on factual, historical claims about the details of the Galilean analogue situation. For example, insofar as opponents of the parasciences can show that proponents are basing their comparison to Galileo on various (false) myths about his trial, then the analogy is undermined. This historical grounding of the discussion is even more obvious and explicit from my examples. For in Einstein's appeal to Galileo, I strengthened their analogy by a textual reference to Galileo, quoting a passage from the Dialogue that expresses (in imaginatively clever language) a methodological principle essentially identical to Einstein's. And in Hume's appeal I criticized his comparison to Galileo by exposing a number of inaccuracies in his reading of Galileo's Dialogue. Of course, in so doing, I was engaged in an evaluation of these examples, and not a mere description. Moreover, it seems clear and obvious from Doury's examples as well as from mine that in appeals to Galileo the strength or weakness of the analogy ought to be based on the historical (and textual) facts pertaining to Galileo; thus, people 
engaged (at the ground level) in controversies about the parasciences, and scientists and philosophers engaged in methodological decisions, as well as scholars theorizing about the appeal to Galileo, have a methodological duty to seek and gain reliable information about Galileo's life, scientific work, methodology, and argumentative practice.

And this brings us to some more evaluative issues. On this topic, it is useful to recall Doury's deliberate and self-reflective descriptivism, meaning that she refrains from formulating and advocating normative or evaluative conclusions, although her descriptive account does include a description of arguers' evaluative practices. Recall, for example, that she describes three ways in which opponents of the parasciences try to refute the appeals to Galileo by the proponents. However, this is a limitation which we need not accept, for many reasons, not the least of which is this: given that (in debates about parasciences and other contexts) arguers not only advance arguments that have a certain structure and form, but also evaluate, criticize, or attempt to refute one another, it would seem quite proper for anyone engaged in argumentation to engage not only in interpretive practices, but also in evaluative or normative ones; now scholars of logic and argumentation theory are often and perhaps typically engaged in argumentation (albeit meta-argumentation); therefore, they should not avoid what is a typically part of argumentation, namely they should attempt to justify normative or evaluative claims.

Let us now focus on the three ways in which opponents react to arguers who appeal to Galileo. It seems to me that such reactions should be conceptualized as criticism and not as "refutations." Doury usually speaks of "refutations" (1993, p. 128; 1997, p. 160), which I believe is too strong a notion, because it conveys a connotation of finality or conclusiveness that is misleading. Of course, one could say that she does not mean actual refutations, but rather attempted refutations, which does convey the right meaning. Moreover, it could be that the French réfutation has a weaker meaning that the English refutation, although I don't think that is the case. Using the concept of criticism would mean that critics of the appeal to Galileo advance various negative or unfavorable evaluations which they would normally try to justify or be required to justify. In other words, such critics should be seen as advancing counter-arguments or metaarguments, which then could themselves be discussed and evaluated. Such a re-labeling (or better, re-conceptualization) is analogous to what is required, in my view and also as plausibly 
argued by Johnson (2013), concerning the talk of "defeaters" of arguments, stemming from Pollock (1995, 2008); that is, the notion of "defeating" an argument also conveys an over-simplified view of argument analysis and evaluation.

Next, concerning the first manner of criticizing appeals to Galileo, namely questioning the analogy, already discussed, it is useful to add something besides merely describing that opponents of such appeals often do this. That is, we can add that it is quite proper to do so, namely to evaluate an argument from analogy by examining the strength or weakness of the analogy. This is a very basic and elementary normative principle, but there is no good reason to join descriptivists in being silent about it.

\subsection{A fallacy of appeal to unpopularity?}

Concerning the second type of criticism of the appeal to Galileo, the situation is much more complex. Recall that Doury (1993, p. $130 ; 1997$, p. 162) describes such critics as objecting that an appeal to Galileo amounts to "reasoning according to which the unlikelihood of a theory would be a decisive reason for its truthfulness," which is a "pernicious ... aberrant ... paralogism." Here it should be stressed that such a description is intended by Doury to be, or at least to correspond, to the critics' own description of what they are doing; indeed the formulation just quoted from Doury is essentially a paraphrase of the one given by one of these critics (Alcock 1989, p. 208). And this intended correspondence is part of Doury's linguistic, descriptive approach elucidated earlier.

Nevertheless, whether this description is that of the analyst, or that of the debate participants, or both, I believe it needs considerable reconstruction.

First, in the context of the present discussion, we need to make a qualification to the effect that this second criticism applies to the specific appeals to Galileo's trial, and not to the general appeals to Galileo's methodology. Doury did not need to make this qualification since she was considering only the former kind of appeal to Galileo. And this qualification is meant to be not only empirically descriptive, but also evaluatively normative in the sense that it would be improper or irrelevant to advance such criticism against appeals to Galileo's general methodology.

Second, we should drop the talk of "decisive reason," as being unrealistic, i.e., empirically and descriptively untrue of the 
relevant argumentative practice. No one in their right mind would think that the universal (or near-universal) rejection of an idea is a decisive reason for its truth; not even astrologers and creationists are that stupid. Nor are critics typically so uncharitable, unfair, and ineffective as to attribute such reasoning to their opponents; normally, critics know better than to waste their time objecting to such straw arguments.

Third, even with this revision, the rest of the description is self-contradictory, insofar as it is saying that unlikelihood is a reason for likelihood. Again, to attribute such a selfcontradiction to the parascientists or to their critics is more of a reflection of the unsatisfactoriness of the analyst's description than a realistic or charitable reflection of the practitioner's flawed thinking. Thus, let us replace the talk of unlikelihood with the notion of unpopularity, in the sense of rejection by a majority of the relevant cognitive community. And let us replace "truthfulness" by the vaguer "correctness." The result is that in this criticism one is objecting that the appeal to Galileo amounts to arguing that a claim should be accepted because it is generally rejected, or that a claim is likely to be correct because so few people think that it is. We might call such a manner of arguing "appeal to unpopularity," meant to be a contrast to (indeed the reverse of) a popular appeal or ad populum argument. Some scholars have already catalogued such an argument form, calling it "negative argument from consensus," contrasting it to the usual "argument from consensus," and regarding it as a special case of the "argument against the person" (Salmon 1984, p. 104).

Finally, Doury also describes the criticism as charging that the appeal to Galileo is a "pernicious and aberrant paralogism." And she suggests that the charge is that the appeal is a special case of affirming the consequent (Doury 1997, 162; 1993, 130), along the following lines: the current scientific community generally rejects this parascientific claim; if such a claim were part of a new paradigm leading to a scientific revolution, then it would be generally rejected by the current scientific community; therefore, this parascientific claim is to be accepted as being part of a new scientific paradigm leading to a scientific revolution. Doury also explicitly indicates that such an argument would be presupposing Kuhn's (1970) account of scientific revolutions in order to support the conditional claim in the second premise.

Now, it is tempting to reconstruct or redescribe this part of the description as charging that the appeal to Galileo is a fallacy; such a redescription, together with all the other strands of the reconstruction, would yield that such critics are objecting that 
the appeal to Galileo commits the fallacy of appealing to unpopularity; and this, in turn, would add a new fallacy to the various lists. However, it is best to resist such a temptation, again out of charity to the critics; for if we take them to be really making a fallacy-charge, then we could require them to justify their charge by showing that such an appeal to unpopularity satisfies all the conditions of what a fallacy is. But, as Woods (2013; cf. Finocchiaro 2014a) has recently stressed, there are at least five such necessary conditions; that is, a fallacy is a (1) common (2) type of (3) argument that (4) appears to be correct but is (5) actually incorrect, ${ }^{9}$ and hence fallacy charges are easier said than justified. Thus, let us simply interpret this element of this criticism of the appeal to Galileo as charging that such an appeal is erroneous or incorrect.

There is no question that sometimes the critics of the appeal to Galileo come close to charging that arguing in that manner is an erroneous appeal to unpopularity. Similarly, there is no doubt that sometimes partisans of the parasciences make appeals to Galileo that come close to being appeals to unpopularity. However, how close the two sides are to actually doing these things respectively depends on the details of what is said in the particular case. As far as general considerations are concerned, I believe the main issue is the following.

I have already suggested that the deductivist version of the appeal to unpopularity is too obviously erroneous to be attributed to anybody; that is, the version claiming: almost everyone rejects proposition $\mathrm{p}$; therefore it follows necessarily that $\mathrm{p}$ is true. However, it seems to me that the same obvious erroneousness also characterizes other weaker versions, e.g.: the probabilistic version that almost everyone rejects $p$, so $p$ is probably true; and the possibilistic version that almost everyone rejects $p$, so $p$ may be true. On the other hand, if the appeal is interpreted as a case of affirming the consequent with Kuhnian presuppositions (as suggested by Doury), then the appeal would not be completely, or necessarily, or always erroneous; for although it is obviously deductively invalid and as it stands inductively weak, its degree of weakness would depend on whether unpopularity was being explained only in terms of a Kuhnian scientific

\footnotetext{
${ }^{9}$ However, see the useful criticism of such a thesis advanced by Hansen 2002. Still, I do not think his criticism undermines my main point here, partly because the target of his criticism is a much more oversimplified concept of fallacy than the one formulated here; for example, he neglects conditions (1) and (2), and limits condition (5) to deductive invalidity or inductive weakness.
} 
revolution and paradigm shift; usually other explanatory factors would be offered.

Moreover, recall that the appeal to Galileo is supposed to be an argument from analogy. Now, the unpopularity of the arguer's claim is usually part of the alleged analogy between the present situation and that of Galileo. Thus, the unpopularity of the idea is not normally given as a reason (whether weak, strong, or decisive) for the probable truth of the parascientific claim. As we have seen, the partisans of the parasciences can certainly be challenged about the strength of their analogy, and if they cannot defend the analogy judgment in other ways than on the basis of their respective unpopularity, the analogy will be very weak. But usually unpopularity is not the only similarity to which they appeal.

Thus, I don't think that this second criticism of the appeal to Galileo is often correct or effective. Indeed, I am not sure we really have a distinct kind of criticism, different from the criticism of the analogy.

\subsection{Appeal to counter-examples}

The third type of criticism described by Doury is, as we saw earlier, the appeal to other precedents that support a conflicting conclusion. That is, sometimes opponents of the parasciences answer by appealing to "other events in the history of science when a new theory, which at first had been given some credence, ended up being rejected as erroneous" (Doury 1997, p. 162). To Doury's examples of Blondot's N-rays, Benoît's artificial manipulation of heredity, and Summerlin's skin transplants in mice, we may add the more spectacular and notorious case of "cold fusion" in 1989; this case was the alleged discovery that thermonuclear energy could be produced with a simple tabletop battery-like apparatus in which heavy water with a palladium electrode immersed in it undergoes electrolysis (Fleischmann and Pons 1989).

Doury makes it sound as if here the critic is subjecting the appeal to Galileo to a kind of internal criticism. This is the impression conveyed when Doury says that "the advantage of the refutation by precedent is the argumentative symmetry which it implies. If the partisan of the parasciences has utilized the appeal to Galileo, that means that he accepts the [appeal to] precedent as a valid form of argumentation; he is then obliged to grant it to his opponent" (Doury 1997, p. 164). Again, as done before, "valid" should be replaced by "correct," in the general 


\section{Finocchiaro}

sense that includes not only deductive validity but also inductive strength, plausibility, and weak support; for there is no good reason in this context to attribute deductivism to either side (whether proponent or opponent).

With this proviso, such criticism may perhaps be interpreted as ad hominem argumentation in the seventeenth-century meaning of this term, adopted by Galileo himself as well as Locke, and exploited fruitfully and elegantly in the twentieth century by Johnstone $(1959,1978$; cf. Finocchiaro 2005, pp. 277-91, 329-39). That is, so understood, an ad hominem argument is one in which the arguer criticizes opponents by deriving conclusions unacceptable to them from premises accepted by them, but not necessarily by the arguer. This is a correct and powerful method of criticism, and should not be confused with the common contemporary conception that defines the ad hominem as the alleged fallacy of criticizing an argument by criticizing the motives and circumstances of the arguer, rather than the content and substance of the argument.

However, I am not sure such an ad hominem interpretation is tenable. For it should be stressed that here the critic is calling attention not to the initial unpopularity of the claims in the precedent cases, which is the focus of the second alleged criticism discussed above, but rather to the initial credibility or interest of those precedent claims. That is, it seems to me that the criticism amounts to an argument from analogy, such that the situation together with the claims of the parascientist is compared to that of the counter-examples, and then the critic concludes that the parascientific claim has as little likelihood of being correct as the claims of the other precedent cases. How does this affect the original appeal to Galileo?

Now, as already clarified, the original appeal to Galileo is itself first and foremost an argument from analogy; it is not primarily an appeal to unpopularity, unless the arguer is basing the alleged analogy only on the unpopularity, which is typically not the case. Thus, the criticism here amounts to responding to an argument from analogy with another argument from analogy where the second analogue (the other precedents or counterexamples) is different from the original one (Galileo). It follows further that the critic is not making, and does not need to make, the concession that such appeals are correct, for both sides know that analogical arguments are correct insofar as they go, but that their strength depends on the strength of the analogy, and that is why they usually focus on the analogy claim. The effect of the criticism is to complicate the discussion by introducing another 
issue besides the one of the strength or weakness of the analogy between Galileo and the current case; the additional issue is whether this analogy, however strong or weak it may be, is stronger than the other analogy between the current case and the counter-examples (such as the cold-fusion case).

How do we compare the two analogies? Doury suggests that that the greater notoriety of Galileo's trial gives the appeal to Galileo greater strength than the criticism of appeal to counter-examples. In fact, referring to such criticism, she says that "its weakness lies in the fact that there exists no counterexample which enjoys the same notoriety as Galileo: Summerlin or Blondot are perfectly unknown to the public at large, and are less apt to convince than Galileo, whose myth is still pregnant with considerable meaning" (Doury 1997, p. 164). I don't think this is right, because the issue is not to compare the two analogues, but the two analogies. There is no question that one analogue (Galileo) is much richer, much better known, and much more extensively mythologized than almost any other, let alone the analogue of counter-examples like Summerlin, Blondot, or Benoît. But these same features of the Galilean analogue make the analogy between it and one's own present case more difficult and problematic, because those exceptional qualities would make is less likely that the analogy holds and would tend to discourage most ordinary persons from even comparing themselves to Galileo. From this point of view, the comparison with the more ordinary cases, when the results were unsuccessful or falsified discoveries, would be easier to make.

My conclusion is that the third criticism of the appeal to Galileo described by Doury may be called appeal to counterexamples. It is best conceptualized as an argument from analogy which uses such counter-examples as analogues to the parascientific situation, and which concludes that the parascientific claim is similarly false or unlikely or unpromising. Such criticism is neither always correct nor always incorrect; its correctness or strength depends not only on the strength of the analogy between the parascientific situation and that of the counterexamples, but also on the relative strength of this analogy vis-àvis the other analogy between the parascientific situation and Galileo. 


\section{Finocchiaro}

\section{Epilogue}

This essay has been a critical appreciation of Marianne Doury's account of the appeal to Galileo. Her account is part of a study of argumentation occurring in debates about the parasciences; these are subjects such as astrology, parapsychology, homeopathy, and alternative medicines. She studies such debates following an approach that is linguistic, descriptive, dissensusoriented, rhetorical, tripolar, and interactionist. The corpus or data base of her investigation is transcriptions of debates broadcast on French TV in 1988-1993.

Doury found that a common argument by defenders of the parasciences is the appeal to Galileo, that is, a form of argument in which they compare themselves to Galileo and their opponents to the inquisitors persecuting him. She analyzes such a form of arguing as an argument from analogy, with the additional step that the analogy is justified based on a number of alleged similarities between the parascientific situation and Galileo's. For example, they allege that their critics are opponents of scientific progress and have unscientific motivations. In accordance with the interactionist element of her approach, she also describes three ways in which the opponents of parasciences react to the appeal to Galileo. That is, critics question the analogy between parascientists and Galileo by pointing out various differences; they charge that such appeals to Galileo amount to committing the fallacy of appealing to unpopularity; and they appeal to various counter-examples in the history of science when minority views were not subsequently vindicated but rather falsified.

Throughout the account, Doury gives numerous examples not only from the debates over the parasciences, but also from the Lysenko affair and from a controversy known as the Benveniste affair. This controversy flared up in 1988 and involved the alleged discovery (later universally rejected) that some antigens dissolved in water can produce their allergic reactions even when they have been diluted away by numerous repeated dilutions.

After such a summary of Doury's account, my appreciation consisted of an empirical historical confirmation of her discovery. That is, one of her main contributions may be taken to be the empirical discovery that the appeal to Galileo occurs frequently in debates over the parasciences, as well as in the Lysenko and Benveniste affairs. My confirmation consisted of presenting considerable historical and empirical evidence that the 
argument form "appeal to Galileo" is also common in many other contexts: creationist arguments against the theory of evolution; criticism and denials of claims about global warming and/or climate change; defenses of global warming and/or climate change, claiming that such investigations have now reached the status of settled science; arguments by scientific classics such as Einstein and Newton, in which they justify some methodological decisions which they have made in their scientific practice by appealing to Galileo's methodology; and arguments by philosophical classics such as Hume and Kant, in which they try to justify some of their fundamental claims and/or some features of their approach on the basis of their analogy with similar claims advanced by Galileo or approaches followed by him.

My appreciation of Doury's account also included an endorsement of her analysis of the appeal to Galileo as an argument from analogy, which also tries to justify the analogy, and which is often criticized by questioning the analogy. Thus, it may be also useful to stress that such appeals to Galileo have the complex structure of two-step arguments: one step supports the analogy, while the other step supports a conclusion about the present or target analogue based on the same thing being true of the reference or precedent analogue.

My criticism consists of a number of interpretive and evaluative additions and refinements. At the interpretive level, analogical appeals to Galileo fall into two main subtypes: appeals to Galileo's trial and appeals to Galileo's methodology; the distinction depends on whether arguers are comparing their situation to the logic and methodology inherent in the context of the Inquisition trial of Galileo, or in the context of his contributions to physics, astronomy, and instrumentation in general. However, both of these versions of the appeal to Galileo ought to be distinguished from another argumentation technique which also involves appealing to evidence from Galileo, but which should not be labeled "appeal to Galileo": this other technique involves supporting or defending theoretical conclusions about argumentation in general on the basis of evidence consisting of Galileo's argumentative practice, in the context of a historical empirical approach to logic and argumentation theory; moreover, such a technique consists of meta-arguments having the form of inductive generalizations and inferences to the best explanation.

At the evaluative level, first of all, there is no need to accept Doury's descriptivist limitation. With such a broader scope, 
we can then advance the simple evaluative judgment that it is quite proper to criticize appeals to Galileo (trial and methodology) by questioning the analogy. Moreover, it is better to discard Doury's talk of "refutations" of the appeal to Galileo, and conceptualize them as criticism. Nevertheless, the second criticism described by Doury, namely charging that the appeal to Galileo commits the fallacy of appeal to unpopularity, is problematic; for the empirical accuracy of interpreting the Galilean appeal as appeal to unpopularity is questionable; and the incorrectness of such an appeal to unpopularity is not automatic, but depends on the issue of the strength or weakness of the analogy, with regard to which popularity is only one alleged similarity. Finally, with regard to the criticism by appealing to counter-examples, this is a distinct criticism, but its refutational strength depends again on the issue of analogy, although in this case we need to compare and contrast two analogies and not merely two analogues.

Such a critical appreciation also suggests a number of further research problems. For example, we can undertake an empirical search for more examples, of both appeals to Galileo's trial and to his methodology. We can also subject these examples to some analysis. Two examples that cry out for more interpretation and evaluation are the cartoon depicting Kerry as an inquisitor and Galileo as a denier of settled science (Fig. 1) and the portrait of Galileo captioned with a comparison between global warming and the earth's roundness (Fig. 3). We can also elaborate some of the analyses already given, such as the one about Kluger's argument that global-warming deniers make Galileo turn in his grave; its structure is relatively unclear, and so is its similarity to other defenses of settled science. Furthermore, the appeals to Galileo by Hume, Kant, and Ortega y Gasset would seem to open the door to an untapped resource for philosophers.

Finally, one could make a more sustained and systematic study and analysis of the rhetorical aspects of the appeal to Galileo. Here, the first step should perhaps be to collect and recapitulate the rhetorical elements mentioned thus far. For example, we saw that Doury points out that one way in which parascientists justify their alleged similarity to Galileo is by means of an emotional appeal, to the effect that their condition is as full of pathos as Galileo's, and their opponents are as arrogant as his inquisitors. She also points out that it is highly ironical that parascientists should appeal to the father of modern science to argue against the modern scientists who typically dismiss their views as unscientific. And, in connection with the appeal to 
counter-examples, there is also the greater appeal of the Galileo case as compared with any other, stemming from the mythology that grew about him. These and similar aspects of the appeal to Galileo would seem to cry out for serious study.

The value of such a project can be reinforced in two other ways, insofar as it would be in accordance with two important lines of scholarly investigation. First, Galileo's life and work have already attracted considerable scholarly attention from a rhetorical point of view (Feyerabend 1975, Finocchiaro 1980, Moss 1993), in addition to its interest from the points of view of science, methodology, and reasoning. Second, the rhetorical approach to argumentation is a well-established branch of argumentation studies (Perelman and Olbrechts-Tyteca 1969, Tindale 1999), in addition to the approaches that may be labeled logical (formal or informal) and dialectical (or dialogical); this remains true independently of the further issue of how rhetoric should itself be conceived, whether as the domain of persuasion phenomena or of audience effects. Of course, both lines of scholarship should avoid reductionistic and one-sided temptations or pitfalls; that is, one should not pretend that because science has a rhetorical dimension, anything goes in science; nor that, because argumentation can be analyzed from the point of view of persuasion and audience-reaction, its validity and its function in the search for truth do not matter. The just-sketched research project is viable only if such lines of investigations are pursued while avoiding such pitfalls.

Acknowledgements: I am grateful to Marianne Doury for clarifications, comments, references, and other feedback. My thanks also go to two anonymous referees for their appreciation and lengthy comments. I also thank Guillaume Laigle, who first brought to my attention Doury's account of the appeal to Galileo, as well as some other sources; he is a mature and accomplished video editor and scientific popularizer in France, who is also writing a doctoral dissertation in communication studies at the University of Burgundy-Dijon (cf. Laigle 2013, 2014).

\section{References}

Alcock, J. (1989). Parapsychologie, Science ou Magie?. Paris: Flammarion.

Alfonsi, P. (1989). Au Nom de la Science. Paris: Barrault-Taxi. 
Amossy, R. (2009). Argumentation in discourse: A sociodiscursive approach to arguments. Informal Logic 29, 252-67.

Benveniste, J. (1988a). Dr. Jacques Benveniste replies. Nature 334 (28 July), 291.

Benveniste, J. (1988b). Benveniste on the Benveniste affair. $\mathrm{Na}$ ture 335 (27 October), 759.

Bermejo-Luque, L. (2012). A unitary schema for arguments by analogy. Informal Logic 32, 1-24.

Bermejo-Luque, L. (2014). The uses of analogies. In: Ribeiro 2014, 57-72.

Berthod, L. (2010). Galilée en appelle au Saint Office contre ses méchants collègues! At: http://laurent.berthod.overblog.fr/article-galilee-en-appelle-au-saint-office-contre-sesmechants-collegues-47911215.html; consulted on 16 January 2015.

Blair, J.A. (1996). The possibility and actuality of visual arguments. Argument and Advocacy 33, 23-39.

Davenas, E., F. Beauvais, J. Arnara, M. Oberbaum, B. Robinzon, A. Miadonna, A. Tedeschi, B. Pomeranz, P. Fortner, P. Belon, J. Sainte-Laudy, B. Poitevin, and J. Benveniste (1988). Human basophil degranulation triggered by very dilute antiserum against IgE. Nature 333 (30 June), 816-18.

Doury, M. (1993). L'appel à Galilée. In: C. Plantin (Ed.), Lieux Communs: Topoi, Stéréotypes, Clichés (pp. 123-32), Paris: Kimé.

Doury, M. (1997). Le Débat Immobile: L'Argumentation dans le Débat Médiatique sur les Parasciences. Paris: Kimé.

Doury, M. (2005). The accusation of amalgame as a metaargumentative refutation. In: F.H. van Eemeren and P. Houtlosser (Eds.), Argumentation in Practice (pp. 145-61), Amsterdam: John Benjamins.

Doury, M. (2006). Evaluating analogy: Toward a descriptive approach to argumentative norms. In: P. Houtlosser and A. van Rees (Eds.), Considering Pragma-Dialectics: A Festschrift for Frans $H$. van Eemeren on the Occasion of His 60th Birthday (pp.35-49), Mahwah (NJ): Lawrence Erlbaum Associates.

Doury, M. (2009). Argument schemes typologies in practice: The case of comparative arguments. In: Eemeren and Garssen 2009, pp. 141-55.

Doury, M. (2013). The virtues of argumentation from an amoral analyst's perspective. Informal Logic 33, 486-509. 
Doury, M. (2014). How to make figures talk: Comparative argument in TV election night specials. In: Ribeiro 2014, pp. 151-70.

Dove, I.J. (2012) On images as evidence and arguments. In: F.H. van Eemeren and B. Garssen (Eds.), Topical Themes in Argumentation Theory: Twenty Exploratory Studies (pp. 22338), Dordrecht: Springer.

Eemeren, F.H. van, and B. Garssen, eds. (2009). Pondering on Problems of Argumentation. Dordrecht: Springer.

Eemeren, F.H. van, and B. Garssen (2014). Argumentation by analogy in stereotypical argumentative patterns. In: Ribeiro 2014, pp. 41-56.

Eemeren, F.H. van, B. Garssen, E.C.W. Krabbe, A.F. Snoeck Henkemans, B. Verheij, and J.H.M. Wagemans (2014). Handbook of Argumentation Theory. Dordrecht: Springer.

Einstein, A. (1953). Foreword. In Galilei 1967, pp. vi-xx.

Einstein, A. (1954). Ideas and Opinions. Trans. S. Bargmann. New York: Crown Publishers.

Feyerabend, P.K. (1975). Against Method: Outline of an Anarchist Theory of Knowledge. London: NLB.

Finocchiaro, M.A. (1980). Galileo and the Art of Reasoning: Rhetorical Foundations of Logic and Scientific Method. (Boston Studies in Philosophy of Science, vol. 61.) Dordrecht: Reidel (now Springer).

Finocchiaro, M.A., trans. and ed. (1989). The Galileo Affair: A Documentary History. Berkeley: University of California Press.

Finocchiaro, M.A. (2005). Arguments about Arguments: Systematic, Critical, and Historical Essays in Logical Theory. New York: Cambridge University Press.

Finocchiaro, M.A. (2010). Defending Copernicus and Galileo: Critical Reasoning in the Two Affairs. (Boston Studies in the Philosophy of Science, vol. 280.) Dordrecht: Springer.

Finocchiaro, M.A. (2013). Meta-argumentation: An Approach to Logic and Argumentation Theory. (Studies in Logic, vol. 42.) London: College Publications.

Finocchiaro, M.A. (2014a). Essay-review of J. Woods's Errors of Reasoning: Naturalizing the Logic of Inference. Argumentation 28, 231-39.

Finocchiaro, M.A. (2014b). Routledge Guidebook to Galileo's Dialogue. ("Routledge Guides to the Great Books.") London: Routledge, Taylor \& Francis Group. 
Finocchiaro, M.A. (2015). The fallacy of composition: Guiding concepts, historical cases, and research problems. Journal of Applied Logic, vol. 13, issue 2, part B, June 2015, pp. 24-43.

Fischer, D. (2011). 'Galileo Movement' fuels climate change divide in Australia. Scientific American, 16 August 2011; (consulted 20 January 2015), available at:

http://www.scientificamerican.com/article/galileo-movementfuels-australia-climate-change-divide/?print=true

Fleischmann, M., and S. Pons (1989). Electrochemically induced nuclear fusion of deuterium. Journal of Electroanalytical Chemistry 261, 301-308. Doi:10.1016/00220728(89)80006-3.

Galilei, Galileo (1967). Dialogue Concerning the Two Chief World Systems, Ptolemaic and Copernican. 2nd edn. Trans. and ed. S. Drake. Berkeley: University of California Press. First edn. 1953.

Garssen, B. (2009). Comparing the incomparable. In: Eemeren and Garssen 2009, pp. 133-40.

Goodwin, J. (2007). What, in practice, is an argument? In: H.V. Hansen, C.W. Tindale, J.A. Blair, R.H. Johnson, and D.M. Godden (Eds.), Dissensus and the Search for Common Ground: Proceedings of the 2007 International Conference of the Ontario Society for the Study of Argumentation (OSSA) (pp. 1-12), Windsor, ON: OSSA. CD-ROM. ISBN 978-09683461-5-0.

Govier, T. (1989). Analogies and missing premises. Informal Logic 11, 141-52.

Groarke, L. (1996). Logic, art and argument. Informal Logic 18, $105-31$.

Guarini, M. (2004). A defence of non-deductive reconstructions of analogical arguments. Informal Logic 24, 153-68.

Hansen, H.V. (2002). The straw thing of fallacy theory: The standard definition of 'fallacy'. Argumentation 16, 133-55.

Hawking, S.W. (1988). A Brief History of Time. New York: Bantam Books.

Hume, D. (1947). Dialogues Concerning Natural Religion. Ed. N. Kemp Smith. Indianapolis: Bobbs-Merrill.

Johnson, R.H. (2013). Defeasibility from the perspective of informal logic. In: D. Mohammed and M. Lewiński (Eds.), Virtues of Argumentation: Proceedings of the 10th International Conference of the Ontario Society for the Study of Argumentation (OSSA), 22-26 May 2013 (pp. 1-12), Windsor, ON: OSSA. 
Johnstone, H.W., Jr. (1959). Philosophy and Argument. University Park: Pennsylvania State University Press.

Johnstone, H.W., Jr. (1978). Validity and Rhetoric in Philosophical Argument. University Park: The Dialogue Press of Man \& World.

Kant, I. (1965). Critique of Pure Reason. Trans. N. Kemp Smith. New York: St. Martin's Press.

Kaufmann, A. (1993). L'affaire de la mémoire de l'eau: Pour une sociologie de la communication scientifique. Réseaux, vol. 11 , no. 58 , pp. 67-89.

Kerry, J. (2014). Remarks on climate change. At:

http://www.state.gov/secretary/remarks/2014/02/221704.htm. Consulted on 20 November 2014.

Kluger, J. (2014). The science of stupid: Galileo is rolling over in his grave. Time, 17 February 2014; (consulted on 3 March 2014), at : http://science.time.com/2014/02/17

Krauthammer, C. (2014). The myth of 'settled science'. Washington Post, 20 February 2014; (consulted on 23 February 2014), at: http://www.washingtonpost.com/opinions/charleskrauthammer-the-myth-of-settledscience/2014/02/20/c1f8d994-9a75-11e3-b9310204122c514b_story.html

Kuhn, T.S. (1970). The Structure of Scientific Revolutions. Second edn., enlarged. Chicago: University of Chicago Press.

Langmuir, I. (1953). Colloquium on pathological science. At: https:/www.cs.princeton.edu/ ken/Langmuir/langmuir.htm. Consulted on 8 December 2014.

Maddox, J. (1988a). Waves caused by extreme dilution. Nature 335 (27 October), 760-63.

Maddox, J. (1988b). When to believe the unbelievable. Nature 333 (30 June), 787.

Maddox, J., J. Randi, and W.W. Stewart (1988). 'High-dilution' experiments a delusion. Nature 334 (28 July), 287-90.

Morris, H.M., and G.E. Parker (1987). What is Creation Science? Revised and expanded edn. Green Forest, AR: Master Books.

Moss, J.D. (1993). Novelties in the Heavens: Rhetoric and Science in the Copernican Controversy. Chicago: University of Chicago Press.

Newton, I. (1999). The Principia: Mathematical Principles of Natural Philosophy. Trans. and ed. I.B. Cohen and A. Whitman. Berkeley: University of California Press. 
Numbers, R.L. (2009). Myth 24: That creationism is a uniquely American phenomenon. In: R.L. Numbers (Ed.), Galileo Goes to Jail and Other Myths about Science and Religion (pp. 215-23), Cambridge: Harvard University Press.

Ortega y Gasset, J. (1956). En Torno a Galileo. Madrid: Revista de Occidente.

Ortega y Gasset, J. (1958). Man and Crisis. Trans. M. Adams. New York: Norton.

Perelman, Ch., and L. Olbrechts-Tyteca (1969). The New Rhetoric: A Treatise on Argumentation. Trans. J. Wilkinson and P. Weaver. Notre Dame: University of Notre Dame Press.

Plantin, C. (1990). Essais sur l'Argumentation: Introduction à l'Étude Linguistique de la Parole Argumentative. Paris: Editions Kimé.

Plantin, C. (2005). L'Argumentation: Histoire, Théories, Perspectives. Paris: Presses Universitaires de France.

Plantin, C. (2011). Les Bonnes Raisons des Émotions: Arguments, Fallacies, Affects. Bern: Peter Lang.

Pollock, J. (1995). Cognitive Carpentry. Cambridge: MIT Press.

Pollock, J. (2008). Defeasible reasoning. In: J.E. Adler and L.J. Rips (Eds.), Reasoning: Studies of Human Inference and its Foundations (pp. 451-70), Cambridge: Cambridge University Press.

Pracontal, M. De (1990). Les Mystères de la Mémoire de l'Eau. Paris: La Découverte.

Ribeiro, H.J., ed. (2014). Systematic Approaches to Argument by Analogy. Dordrecht: Springer.

Salmon, W.C. (1984). Logic. 3rd edn. Englewood Cliffs, NJ: Prentice-Hall.

Tindale, C.W. (1999). Acts of Arguing: A Rhetorical Model of Argument. Albany: State University of New York Press.

Waller, B. (2001). Classifying analogies. Informal Logic 21, 199-218.

Walton, D.N. (2014). Argumentation schemes for argument from analogy. In: Ribeiro 2014, pp. 23-40.

Walton, D., C. Reed, and F. Macagno (2008). Argumentation Schemes. Cambridge: Cambridge University Press.

Woods, J. (2013). Errors of Reasoning: Naturalizing the Logic of Inference. London: College Publications. 